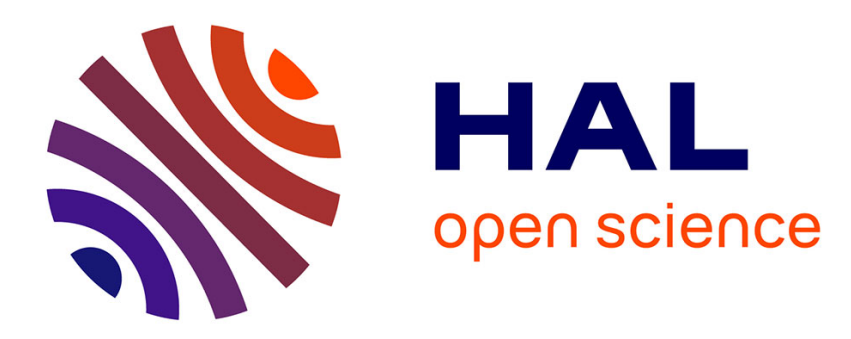

\title{
Modeling aeolian erosion in presence of vegetation
}

Samuel Dupont, G. Bergametti, Serge Simoëns

\section{To cite this version:}

Samuel Dupont, G. Bergametti, Serge Simoëns. Modeling aeolian erosion in presence of vegetation. Journal of Geophysical Research: Earth Surface, 2014, 119 (2), pp.168-187. 10.1002/2013JF002875 . hal-01296881

\section{HAL Id: hal-01296881 \\ https://hal.science/hal-01296881}

Submitted on 11 Apr 2016

HAL is a multi-disciplinary open access archive for the deposit and dissemination of scientific research documents, whether they are published or not. The documents may come from teaching and research institutions in France or abroad, or from public or private research centers.
L'archive ouverte pluridisciplinaire HAL, est destinée au dépôt et à la diffusion de documents scientifiques de niveau recherche, publiés ou non, émanant des établissements d'enseignement et de recherche français ou étrangers, des laboratoires publics ou privés. 


\section{Journal of Geophysical Research: Earth Surface}

\author{
RESEARCH ARTICLE \\ 10.1002/2013JF002875 \\ Key Points: \\ - A saltation model is extended to \\ vegetated surfaces \\ - Soil erosion patterns are consistent \\ with previous observations \\ - Soil erosion reduction is quantified \\ following plant distribution
}

Correspondence to:

S. Dupont,

sylvain.dupont@bordeaux.inra.fr

\section{Citation:}

Dupont, S., G. Bergametti, and S. Simoëns (2014), Modeling aeolian erosion in presence of vegetation, $J$. Geophys. Res. Earth Surf., 119, 168-187, doi:10.1002/2013JF002875.

Received 6 JUN 2013 Accepted 30 DEC 2013 Accepted article online 4 JAN 2014 Published online 6 FEB 2014

\section{Modeling aeolian erosion in presence of vegetation}

\author{
S. Dupont ${ }^{1,2}$, G. Bergametti ${ }^{3}$, and S. Simoëns ${ }^{4}$ \\ 'INRA, UMR 1391 ISPA, F-33140, Villenave d'Ornon, France, ${ }^{2}$ Université de Bordeaux, UMR 1391 ISPA, F-33170, Gradignan, \\ France, ${ }^{3}$ LISA (Laboratoire Interuniversitaire des Systèmes Atmosphériques), UMR CNRS 7583 Universités Paris Diderot and \\ Paris Est, Créteil, France, ${ }^{4}$ LMFA, UMR CNRS 5509, Ecole Centrale de Lyon, Université de Lyon I, INSA Lyon, Ecully \\ CEDEX, France
}

\begin{abstract}
Semiarid landscapes are characterized by vegetated surfaces. Understanding the impact of vegetation on aeolian soil erosion is important for reducing soil erosion or limiting crop damage through abrasion or burial. In the present study, a saltation model fully coupled with a large-eddy simulation airflow model is extended to vegetated landscapes. From this model, the sensitivity of sand erosion to different arrangements and type of plants (shrub versus tree) representative of semiarid landscapes is investigated and the wind erosion reduction induced by plants is quantified. We show that saltation processes over vegetated surfaces have a limited impact on the mean wind statistics, the momentum extracted from the flow by saltating particles being negligible compared to that extracted by plants. Simulated sand erosion patterns resulting from plant distribution, i.e., accumulation and erosion areas, appear qualitatively consistent with previous observations. It is shown that sand erosion reduction depends not only on vegetation cover but also on plant morphology and plant distribution relative to the mean wind direction. A simple shear stress partitioning approach applied in shrub cases gives similar trends of sand erosion reduction as the present model following wind direction and vegetation cover. However, the magnitude of the reduction appears significantly different from one approach to another. Although shrubs trap saltating particles, trees appear more efficient than shrubs to reduce sand erosion. This is explained by the large-scale sheltering effect of trees compared to the local shrub one.
\end{abstract}

\section{Introduction}

Understanding and quantifying aeolian soil erosion in vegetated landscapes is important for many reasons. First, semiarid areas are characterized by heterogeneous seasonal vegetation going from grassland to shrubland, to woodland, and represent a significant source of dust in the atmosphere [IPCC, 2007]. These regions appear more sensitive than others to climate change and are subject to increasing human activities [Huang et al., 2010]. These perturbations should modify the dust emission from these regions. Second, in agricultural areas, wind-blown sand can damage young crops or orchards plants through abrasion [Skidmore, 1966; Armbrust and Retta, 2000] or burial/uprooting [Fryrear and Downes, 1975; Sterk, 2003], and wind-blown dust can impoverish soil in organic matters and nutrients [Field et al., 2010]. Identifying good landscape management practices is needed to reduce soil erosion in agricultural areas. Third, plant regeneration and tree planting are commonly used methods to reduce soil erosion in regions subject to desertification such as in China [Li et al., 2004]. Our knowledge on the efficiency of plantings to reduce soil erosion following their shape and arrangement needs to be improved. Since saltation is a key process in soil erosion as it is the primary driver for sediment movement and dust emission, this paper is focusing on saltation over flat sand beds covered with sparse vegetation.

Previous field [Lancaster and Baas, 1998; Gillette and Pitchford, 2004; King et al., 2006; Leenders et al., 2007; Li et al., 2007; Bergametti and Gillette, 2010] and wind-tunnel [Van de Ven et al., 1989; Udo and Takewaka, 2007; Burri et al., 2011; Youssef et al., 2012] experiments have analyzed the impact of sparse vegetation on soil erosion. Vegetation reduces soil erosion through three mechanisms [Wolfe and Nickling, 1993]: the vegetation sheltering of a portion of the erodible surface, the reduction of the wind velocity through vegetation momentum extraction, and the vegetation trapping of saltation particles. The contribution of these three mechanisms changes with vegetation type, cover, and arrangement. For example, Leenders et al. [2007] observed that the main mechanism induced by shrubs is to trap sand particles while the main mechanism induced by trees is to reduce the wind velocity near the surface over a large area. Li et al. [2007] also observed that sparsely distributed mesquites are less efficient at reducing aeolian soil erosion 
than grasses. This was explained by the presence in the former surface of "streets" of bare soil that results from the preferential alignment of mesquites along the main wind direction [Okin and Gillette, 2001; King et al., 2006].

Lancaster and Baas [1998] derived a simple predictive equation of soil erosion reduction due to the presence of vegetation where soil erosion decreases exponentially with vegetation cover. However, this relationship is not adapted to all types of sparse vegetation encountered in semiarid regions and it does not account for specific alignment of vegetation or for plant frontal density. With a more physical approach, Raupach et al. [1993] and Okin [2008] proposed two simple models to quantify the influence of vegetation on sediment flux based on the shear stress partitioning theory. This theory accounts for the sheltering capacity of vegetation by partitioning the wind momentum absorbed by the vegetation and by the ground surface through the ratio of the friction velocity behind the vegetation and above a similar surface without vegetation. The saltation flux is then deduced from a parameterization depending on the local friction wind velocity such as the one proposed by Shao et al. [1993]. While the model of Raupach et al. [1993] is based on the knowledge of the vegetation dimension and assumes a homogeneous spatial distribution of vegetation elements, the model of Okin [2008] is based on the size distribution of erodible gaps between vegetation elements. Both models were applied quite successfully against wind-tunnel and field measurements over various types of roughness elements. However, the reliance of these models on vegetation or gap distribution makes them difficult to apply to field sites without first performing a calibration of the model on the site. More complex models of wind-blown sediments have been also developed and applied over individual plants [Leenders et al., 2011] and surfaces with small heterogeneous vegetation patterns [Bowker et al., 2007]. However, these models simplified the wind flow and parameterized the sand transport, which makes them difficult to export to sites other than the site of their validation/calibration.

As reviewed in Dupont et al. [2013] (hereafter referred to as Du2013), physically based saltation models on bare sands have been proposed in the literature accounting for (1) individual particle trajectories, (2) ejection or splash of particles at the surface, (3) wind velocity reduction within the saltation layer, and (4) steady state of the saltation layer [Ungar and Haff, 1987; Werner, 1990; Anderson and Haff, 1988; Shao and Li, 1999; Doorschot and Lehning, 2002; Andreotti, 2004; Almeida et al., 2006; Kok and Renno, 2009]. However, none of them have been applied over heterogeneous vegetated surfaces because of their coarse parameterization of the wind flow. Recently, Du2013 developed a new physically based saltation model fully coupled with a large-eddy simulation (LES) airflow model that gives access to instantaneous dynamic fields and thus is capable of reproducing the main wind gusts. Compared to previous saltation models, the model of Du2013 simulates explicitly turbulent flow eddies and their complete interaction with saltation processes. The model has been evaluated on flat sand beds under various wind conditions and sand particle-size distributions. The main characteristics of the saltation layer and their sensitivity to wind conditions were qualitatively and quantitatively consistent with previous observations. The explicit resolution of the turbulent wind flow as permitted by the LES approach makes the model applicable over heterogeneous vegetated landscapes. Over the last decade, it has been demonstrated that the LES technique reproduces the main features of turbulent flow observed over homogeneous [e.g., Shaw and Schumann, 1992; Dupont and Brunet, 2008a] and heterogeneous [e.g., Yang et al., 2006; Dupont and Brunet, 2008b; Dupont et al., 2011] vegetation canopies as well as over forested hills [e.g., Dupont et al., 2008; Ross, 2008]. This approach is therefore promising for simulating sand erosion over vegetated surfaces.

The goals of the present paper are (1) to extend the saltation model of Du2013 to vegetated surfaces, (2) to test the model on different vegetation arrangements and types, over flat sand beds, and for well-developed saltation conditions, and (3) to quantify the reduction of sand erosion following vegetation arrangements and types. Two types of vegetation, representative of semiarid areas, are considered: shrubs with similar characteristics to the Hyphaene thebaica shrub studied by Leenders et al. [2007] in north Burkina Faso, West Africa, and trees with similar characteristics to the olive trees of an orchard in Tunisia, North Africa, studied by Labiadh et al. [2013]. For the first application, we do not try to fit perfectly with the experimental site conditions of Leenders et al. [2007] and Labiadh et al. [2013] because some complexities of these sites are still difficult to account for in our simulations, such as the presence of sand ripples in the olive tree orchard, and because both sites have different soil size distributions, which do not facilitate the comparison between surfaces with shrubs and trees. Consequently, the comparisons with these experiments as well as with other experiments reported in the literature will be mostly qualitative. Quantitative comparisons with 
previous field and model results will be performed on the magnitude of the sand erosion reduction following vegetation cover.

\section{Method}

\subsection{Model}

The Advanced Regional Prediction System (ARPS) version 5.1.5 [Xue et al., 2000, 2001], developed at the Center for Analysis and Prediction of Storms (CAPS) at the University of Oklahoma, is used in this study to simulate, with a LES approach, turbulent wind flow and saltation processes over sparse vegetation. With the LES approach, the conservation equations are implicitly filtered toward the grid, in order to separate the small scales from the large scales. Subgrid scale (SGS) turbulent motions are modeled through a 1.5 order turbulence closure scheme with the resolution of a SGS turbulent kinetic energy (TKE) conservation equation. A saltation model has been introduced inside ARPS by Du2013. This consisted of implementing (1) a Lagrangian particle motion equation that tracks individual particle trajectories, (2) a two-way interaction between the turbulent flow and particle motions, and (3) a splash scheme to account for particle rebound and ejection at the surface. The model considers the following assumptions: (1) particles are spherical with a diameter $d_{p}$, a density $\rho_{p}$, and a mass $m_{p}\left(=\pi d_{p}^{3} \rho_{p} / 6\right) ;(2)$ the ground or sand bed is dry and composed of particles with various diameters that follow a multimodal mass size distribution; (3) particle aerodynamic entrainment from the surface is neglected as only well-developed saltation conditions are considered; (4) the SGS velocity of particles is neglected as the lifetime of the smallest resolved eddies is smaller than the particle response time; (5) interparticle collisions in the air are not considered; and (6) the deformation of the bed surface is neglected during erosion events. The model is further extended to account for the presence of vegetation. To that purpose, the impact of vegetation on the wind flow has to be considered as well as particle deposition on vegetation elements.

The effect of vegetation on the turbulent flow is considered through the introduction of a pressure and viscous drag force term (equation (1)) in the momentum equation (Du2013, equation (1)), and its equivalent term is added in the equation for SGS TKE equation (Du2013, equation (A1)) to preserve the energy budget. The pressure and viscous drag force term is modeled:

$$
F_{\text {vegi }}=-C_{\text {dveg }} A_{\text {fveg }} V u_{i}
$$

where $i$ refers to the streamwise, lateral, and vertical components ( $i=1,2$, and 3 , respectively), $C_{\text {dveg }}$ is the mean drag coefficient of the vegetation, $A_{\text {fveg }}\left(\mathrm{m}^{2} \mathrm{~m}^{-3}\right)$ the frontal area density of the vegetation, $V$ the wind speed magnitude, and $u_{i}$ the grid volume-averaged wind velocity component $\left(u_{1}=u, u_{2}=v\right.$, and $u_{3}=$ $w$, where $u, v$, and $w$ are the streamwise, lateral, and vertical wind velocity components, respectively). This drag force approach is further detailed in Dupont and Brunet [2008a, 2009]. This version of ARPS has been extensively validated against field and wind-tunnel measurements over homogeneous canopies [Dupont and Brunet, 2008a], over simple forest-clearing-forest patterns [e.g., Dupont and Brunet, 2008b; Dupont et al., 2011], over a forested hill [Dupont et al., 2008], and over a waving crop [Dupont et al., 2010].

The particle motion is resolved from an equation of motion accounting for the drag and gravity forces on the particle (see Du2013, equation (3)). The two-way coupling between particle motion and the wind flow occurs through the particle drag force. Because of computational time and memory limitations, only a statistically representative number of particle trajectories is explicitly resolved. To that purpose, a ratio between the real number of particles and the number of numerically resolved particles is introduced in the wind flow conservation equations [see Du2013 for more details]. In other words, each resolved particle is treated as a group of real particles. When a particle reaches the surface, the particle is assumed to rebound, eject other particles, or deposit on the surface following a probabilistic approach [Du2013]. Only splash entrainment of particles from the surface is considered since only well-developed saltation conditions are considered [Anderson and Haff, 1991; Shao and Raupach, 1992]. In the presence of vegetation, neglecting particle aerodynamic entrainment is reasonable as shown by Sutton and McKenna-Neuman [2008b] from a wind-tunnel experiment with solid roughness elements. However, this may be incorrect in slow wind condition as intense bursts coming from above or developing behind roughness elements could be more efficient to entrain sand than the splash process. In the presence of vegetation, a particle can also deposit onto vegetation and be removed from the simulation without resuspension. Deposited particles are assumed to accumulate on the ground although the bed level does not change. The mechanism of deposition is considered as a combination of sedimentation on horizontal surfaces and inertial impaction on vertical surfaces as done for spores 
[McCartney and Fitt, 1985]. The probability that a particle encounters a horizontal vegetation surface during gravitational settling over a time step $d t$ is

$$
P_{\text {sed }}=A_{\text {hveg }} v_{s} d t
$$

where $A_{\text {hveg }}$ is the horizontal area density of the vegetation (which is assumed equal to $A_{\text {fveg }}$ in the present study) and $v_{s}$ is the particle settling velocity $\left(=d_{p}^{2} g \rho_{p} /(18 v \rho)\right.$ where $g$ is the acceleration due to gravity, $v$ is the molecular kinematic viscosity of the fluid, and $\rho$ is the air density).

Due to their inertia, particles do not follow exactly the streamlines around obstacles and so impact on vegetation elements. The probability that a particle encounters a vertical vegetation surface over a time step $d t$ is

$$
P_{\mathrm{imp}}=A_{\mathrm{fveg}} V_{p} E d t
$$

where $V_{p}$ is the horizontal velocity of the particle and $E$ is the efficiency coefficient of the impaction. The latter coefficient is computed from the parameterization proposed by Aylor [1982], which is an approximation of the impaction results of May and Clifford [1967] obtained on a cylinder or ribbon:

$$
E=0.86 /\left(1+0.442 S t^{-1.967}\right),
$$

where $S t$ is the Stokes number, which is a measure of the particle response time to flow motions. The particle response time is computed from the particle settling velocity: $v_{s} / g$. The eddies that influence the particle impaction process have a size of the order of the length scale $I_{\text {veg }}$ of the vegetation elements such as the radius or diameter for cylindrical objects [Legg, 1983]. Therefore, the time characteristic of these flow motions is defined as the ratio between $I_{\text {veg }}$ and the average horizontal wind velocity. The Stokes number is

$$
S t=v_{s} \sqrt{u_{1}^{2}+u_{2}^{2}} /\left(g l_{\text {veg }}\right) \text {. }
$$

\subsection{Numerical Details}

Aeolian erosion of flat dry sand surfaces with sparse vegetation is simulated under a neutral atmosphere. The mass size distribution of the sand is characterized by an unimodal lognormal distribution defined by a median diameter of $\mu_{1}=200 \mu \mathrm{m}$ and a geometric standard deviation of $\sigma_{1}=1$.2. Two types of vegetation elements, representative of semiarid areas, are studied: shrubs with branches reaching the ground and trees with a distinct trunk below the crown. Here, shrubs have similar characteristics as the Hyphaene thebaica shrub studied by Leenders et al. [2007] in north Burkina Faso, West Africa, and trees have similar characteristics as the olive trees of an orchard in Tunisia, North Africa, studied by Labiadh et al. [2013]. Shrubs are represented as an half-ellipsoid of $0.6 \mathrm{~m}$ height, $1.3 \mathrm{~m}$ width, and with a leaf area index (LAl) of about 1 . Olive trees are represented by two cylinders: a narrow one of $1.5 \mathrm{~m}$ height and $0.5 \mathrm{~m}$ diameter representing the trunk, and above a larger one of $4.4 \mathrm{~m}$ diameter representing the tree crown, going up to $4.0 \mathrm{~m}$ height, and with a LAI of about 8 . The length scale $I_{\text {veg }}$ of vegetation elements for the calculation of the Stokes number within the plant foliage (equation (5)) is assumed equal to $0.05 \mathrm{~m}$ for both plant types. This is justified by the similar leaf size between olive trees and shrubs.

Different vegetation covers $c_{v}$ (projected area of the vegetation on the ground) are investigated, going from $0 \%$ (bare sand) to $39 \%$ for shrub cases and $0 \%$ to $2.7 \%$ for tree cases. Following the main wind direction, a total of eight vegetation configurations are studied: five for the shrub cases, referenced hereafter as cases $\mathrm{B} 0$ to B4, and three for the tree cases, referenced as cases T0 to T2. The main characteristics of these configurations are summarized in Table 1 and the spatial arrangements of plants are shown in Figure 1. For some configurations, various wind intensities (saltation friction velocity $u_{* s b}$ ) have been investigated. The bare sand configuration B0 corresponds to cases 1 to 6 presented in Du2013 with different $u_{* s b}$. The case B3 has the same vegetation arrangement as B2 but a different wind direction. In all cases the wind direction is oriented at $45^{\circ}$ from the $x$ axes except in $\mathrm{B} 3$ where the wind is oriented at $22.5^{\circ}$. Note that in $\mathrm{T} 2$, the tree row orientation $\left(38.7^{\circ}\right)$ is slightly different from the mean wind direction $\left(45^{\circ}\right)$. In simulations, the wind direction fluctuations are only due to the flow turbulence and to the flow bypass of plants, as in wind-tunnel experiments. This means that no large-scale wind direction variations are considered during the simulated erosion event, which differs from some real erosion events. The roughness length $z_{0}$ of the sand bed (without accounting for the presence of vegetation) is equal to $10 \mu \mathrm{m}$ in shrub cases and $50 \mu \mathrm{m}$ in tree cases. The $z_{0}$ value of shrub cases is close to the value $z_{0 p}$ of a homogeneous sand bed of uniform $200 \mu$ m diameter particles (assuming that $z_{0 p}=\mu_{1} / 30$ following Nikuradse [1933]) and similar to the sand beds considered in Du2013. The $z_{0}$ value of tree cases was set higher in order to account for the presence of nonerodible roughness elements such as gravel. 


\begin{tabular}{|c|c|c|c|c|c|c|c|c|}
\hline Cases & $C_{v}{ }^{a}$ & $\lambda^{\mathrm{b}}$ & $z_{0}^{c}(\mathrm{~m})$ & $\theta^{\mathrm{d}}\left({ }^{\circ}\right)$ & $L / h^{\mathrm{e}}$ & $u_{* s b}{ }^{f}\left(\mathrm{~m} \mathrm{~s}^{-1}\right)$ & $r_{\text {erod }}{ }^{g}(\%)$ & $r_{\text {erod }}^{*}{ }^{\mathrm{h}}(\%)$ \\
\hline \multicolumn{9}{|c|}{ Shrub Cases } \\
\hline BO & $0 \%$ & - & $10 \times 10^{-6}$ & 0 & - & $0.41 ; 0.54 ; 0.65 ; 0.75 ; 0.93 ; 1.10$ & - & - \\
\hline B1 & $0.4 \%$ & 0.00149 & $10 \times 10^{-6}$ & 45 & $\infty$ & 0.75 & 8 & - \\
\hline B2 & $10 \%$ & 0.044 & $10 \times 10^{-6}$ & 45 & 6.2 & $0.43 ; 0.62 ; 0.91$ & $51 ; 57 ; 49$ & $37 ; 37 ; 44$ \\
\hline B3 & $10 \%$ & 0.044 & $10 \times 10^{-6}$ & 22.5 & 13.7 & 0.90 & 72 & 53 \\
\hline \multicolumn{9}{|c|}{ Tree Cases } \\
\hline T0 & $0 \%$ & - & $50 \times 10^{-6}$ & 45 & - & 0.53 & - & - \\
\hline T1 & $0.3 \%$ & 0.00194 & $50 \times 10^{-6}$ & 45 & $\infty$ & 0.53 & 77 & - \\
\hline $\mathrm{T} 2$ & $2.7 \%$ & 0.01557 & $50 \times 10^{-6}$ & 45 & 6.0 & 0.77 & 83 & - \\
\hline $\begin{array}{l}{ }^{a} \text { Veg } \\
{ }^{b} \text { Rou } \\
{ }^{\mathrm{c}} \mathrm{Gro} \\
{ }^{\mathrm{d}} \mathrm{Me} \\
{ }^{\mathrm{e}} \mathrm{Dis} \\
{ }^{\mathrm{f}} \mathrm{Salt} \\
{ }^{\text {g }} \mathrm{San} \\
{ }^{\mathrm{h}} \mathrm{San}\end{array}$ & $\begin{array}{l}\text { tation c } \\
\text { hness c } \\
\text { id roug } \\
\text { wind c } \\
\text { nce bet } \\
\text { ion fric } \\
\text { erosion } \\
\text { erosion }\end{array}$ & $\begin{array}{l}\text { ver. } \\
\text { nsity. } \\
\text { ness leng } \\
\text { rection rel } \\
\text { een succe } \\
\text { on velocity } \\
\text { reduction } \\
\text { reduction }\end{array}$ & $\begin{array}{l}\text { ive to the } x \\
\text { ive plants in } \\
\text { over an equi } \\
\text { educed from } \\
\text { educed from }\end{array}$ & $\begin{array}{l}\text { is. } \\
\text { ee mear } \\
\text { ent bar } \\
\text { le prese } \\
\text { le appr }\end{array}$ & $\begin{array}{l}\text { wind di } \\
\text { sand. } \\
\text { t mode } \\
\text { ch of } O\end{array}$ & $\begin{array}{l}\text { ction. } \\
\text { in [2008]. }\end{array}$ & & \\
\hline
\end{tabular}

In shrub cases, the computational domain extends over $20 \times 15 \times 12 \mathrm{~m}$. This corresponds to $200 \times 150 \times 100$ grid points in the $x, y$, and $z$ directions, respectively, and to a horizontal resolution $\Delta x$ and $\Delta y$ of $0.10 \mathrm{~m}$. The vertical grid resolution $\Delta z$ is $0.01 \mathrm{~m}$ at the surface, and the grid is stretched above. These domain characteristics are identical to those used in Du2013. In tree cases, the domain size is $74 \times 60 \times 40 \mathrm{~m}$, with $370 \times$ $300 \times 100$ grid points in the $x, y$, and $z$ directions, respectively. The horizontal resolution is $0.20 \mathrm{~m}$, and the vertical grid resolution is $0.01 \mathrm{~m}$ at the surface. This choice of size and resolution of our computational domain results from a compromise between constraints related to the available computational time and the spatial and lifetime resolutions of the main eddies involved in saltation and in presence of sparse vegetation. The grid resolution of the model is fine enough to simulate reasonably well the main eddies within the saltation layer as well as the main eddies developing to the lee of plant elements. However, the size limitation of the domain does not allow large atmospheric surface layer eddies to be resolved since they have a much larger spatial scale than our domain and a much larger lifetime than the duration of our simulation.

The lateral boundary conditions are periodic for both wind flow and particle motion, which allows us to simulate an infinite erodible sand with a regular vegetation arrangement and thus a well-developed saltation layer. The bottom wind boundaries are treated as rigid, and the surface momentum flux is parameterized by using bulk aerodynamic drag laws. The particles are assumed to rebound, eject other particles, or deposit on the surface when they reach the $0.5 \mathrm{~mm}$ layer above the surface. In the lowest grid cell, the horizontal wind velocity components at the particle position were extrapolated from the resolved fluid components of the second grid cell using a logarithmic profile. A $3 \mathrm{~m}$ deep Rayleigh damping layer is used at the upper boundary in order to absorb upward-propagating wave disturbances and to eliminate wave reflection at the top of the domain. Additionally, the flow is driven by a depth-constant geostrophic wind corresponding to a base-state wind at the upper boundary. The velocity fields were initialized using a meteorological preprocessor with a constant vertical profile of potential temperature and a dry atmosphere. The particle motion equation was resolved with the same time step as the momentum equation resolution, which is smaller than particle response time.

Simulations were performed in two steps. The flow dynamic was first solved without saltation. Once the flow dynamic reached an equilibrium state with the surface, then 10000 initial resolved particles were released randomly within the $0.3 \mathrm{~m}$ depth layer above the surface, and the saltation model was activated. Rapidly, the number of particles increases in the domain due to the splashing process of particles impacting the surface. The number decreases and reaches a mean equilibrium state as the mean near-surface wind velocity decreases through particle momentum extraction and equilibrates. At equilibrium state, the number of resolved particles is about 1 million, which correspond to about 300 to 4200 million real particles. Saltation events of $10 \mathrm{~min}$ were simulated. 
(a) Shrub cases
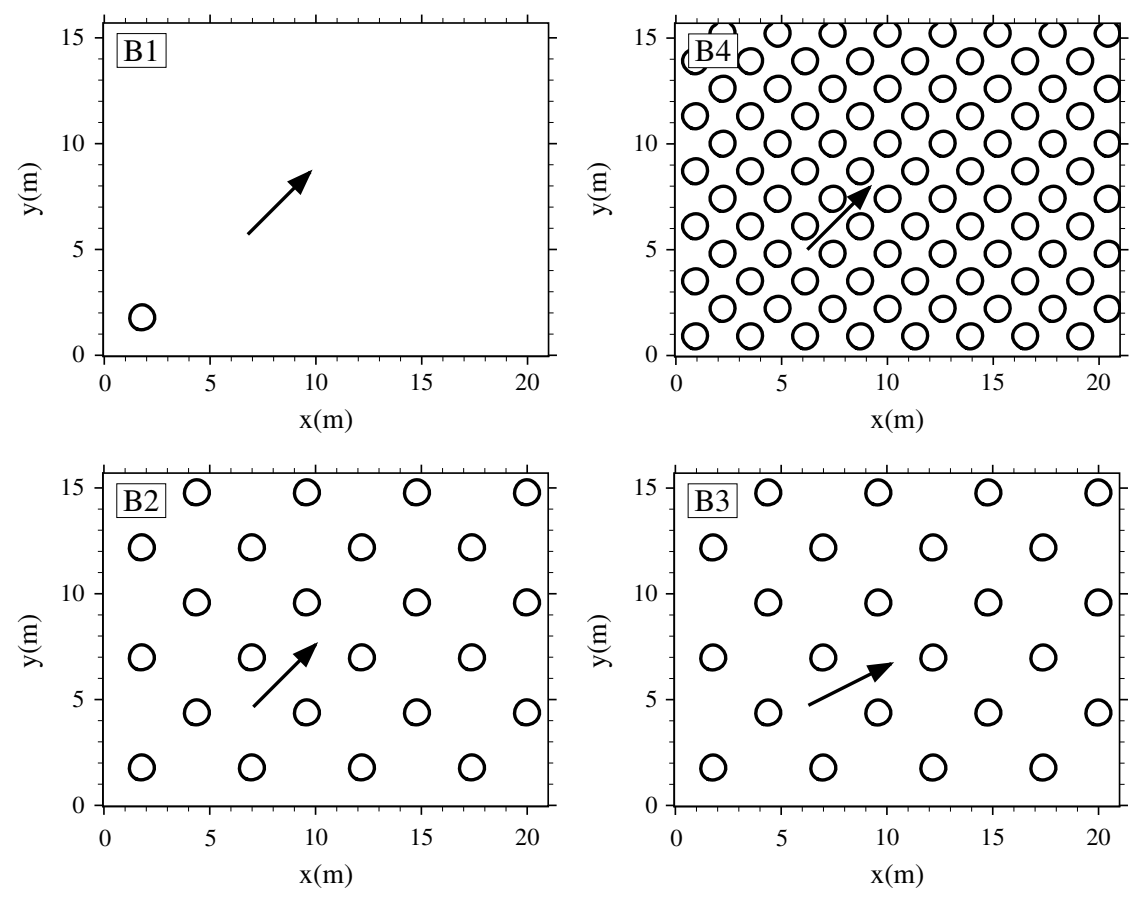

(b) Tree cases
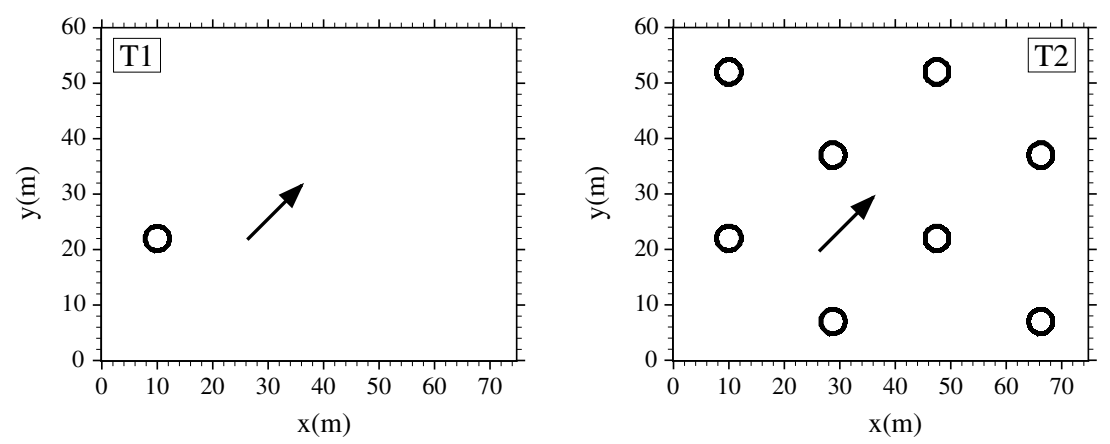

Figure 1. Spatial distribution of plants in the $x-y$ plane for (a) shrub and (b) tree cases. The arrows indicate the mean wind direction. The solid black circles represent the shrubs or tree crowns.

\subsection{Data Analysis}

After the flow and the saltation have reached an equilibrium state, statistics on the wind and sand erosion were computed from a time-averaging procedure performed over 41 samples collected during a $400 \mathrm{~s}$ period, starting $200 \mathrm{~s}$ after initiating saltation. For some variables, a horizontal averaging was performed over all $x$ and $y$ locations at each considered $z$. Consequently, a quantity $\varphi_{i}$ characterizing the wind flow, the saltating particles, or the sand erosion is decomposed into either $\varphi_{i}=\left\langle\varphi_{i}\right\rangle_{\text {txy }}+\varphi_{i}^{\prime}$ or $\varphi_{i}=\left\langle\varphi_{i}\right\rangle_{t}+\varphi_{i}^{\prime \prime}$, where the symbols \langle\rangle$_{t x y}$ and \langle\rangle$_{t}$ denote the space-time and time averages, respectively, and the prime and double primes denote the deviation from the space-time and time averaged values, respectively.

To compare vegetated cases with bare sand cases, in particular in terms of saltation flux, the saltation friction velocity $u_{* s v}$ observed above vegetated surfaces has to be converted into an equivalent saltation friction velocity $u_{* s b}$ observed above a bare sand of $z_{0}=10 \mu \mathrm{m}$ roughness length. To that purpose, we assumed that the mean velocity profiles above both surfaces, the equivalent bare sand and the vegetated surface, are equal at the altitude of $z_{\text {ref }}=20 \mathrm{~m}$ (see Figure 2). Since both profiles are logarithmic, $u_{* s b}$ is deduced as follows:

$$
u_{* s b}=u_{* s v} \log \left(\left(z_{\text {ref }}-d_{s v}\right) / z_{\text {osv }}\right) / \log \left(z_{\text {ref }} / z_{\text {osb }}\right)
$$




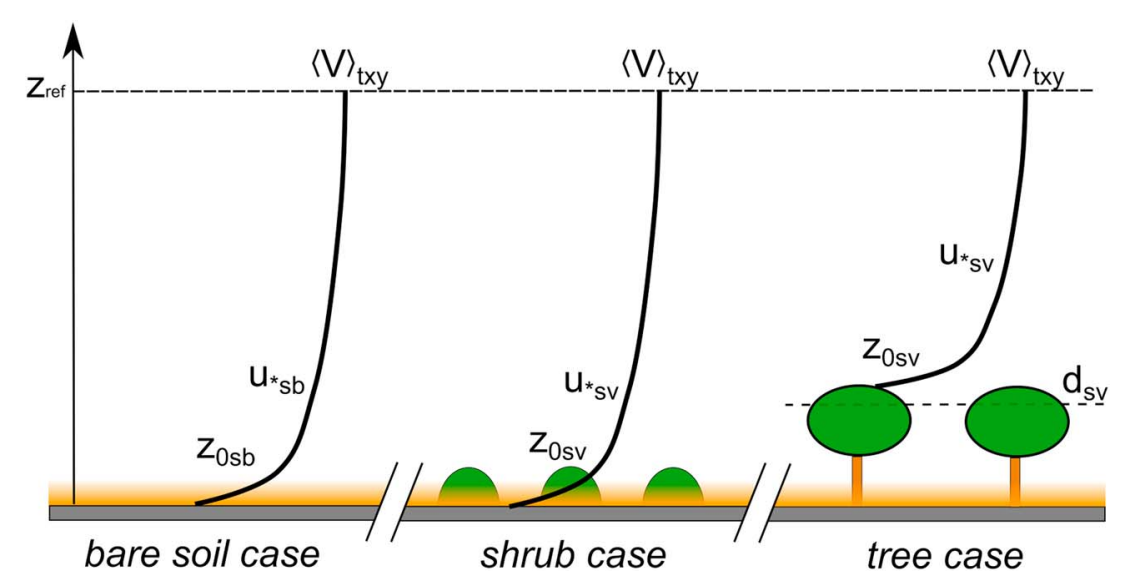

Figure 2. Schematic representation of the calculation of the equivalent saltation friction velocity $u_{* s b}$ over bare sand from the wind profiles simulated over vegetated surfaces composed of shrubs or trees. Wind profiles are logarithmic, and the wind velocities at $\boldsymbol{Z}_{\text {ref }}$ above the bare sand and the vegetated surfaces are assumed equal (see section 2.3 for further details).

where $d_{s v}$ is the saltation displacement height of the vegetated surface (only considered for tree cases), $z_{0 s v}$ is the saltation roughness length of the vegetated surface, and $z_{0 s b}$ is the saltation roughness length of the bare sand. Both $d_{s v}$ and $z_{0 s v}$ are deduced from simulated mean wind velocity and momentum flux profiles. For consistency, $z_{0 s b}$ is estimated from an equation similar to Raupach's [1991] but fitted with saltation roughness lengths obtained by Du2013 over bare sand (see their Figure 3):

$$
z_{0 s b} / z_{0}=\left(A u_{* s b}^{2} / 2 g\right)^{1-r} z_{0}^{r-1},
$$

where $A=0.21, r=u_{* t} / u_{* s b}$ with $u_{* t}$ the threshold friction velocity, and $z_{0}=1 \times 10^{-5} \mathrm{~m}$.

The threshold friction velocity $u_{* t}$ of the sand bed in shrub cases is deduced from the parametrization of Shao and Lu [2000]. However, the roughness length of the sand bed in tree cases is larger than the one of a surface of uniform $200 \mu \mathrm{m}$ diameter particles (see section 2.2). Consequently, $u_{* t}$ is corrected to account for these nonerodible elements by using the physical scheme of drag partition between the roughness elements and the erodible surface proposed by Marticorena and Bergametti [1995]. The efficient friction velocity ratio $f_{\text {eff }}$ defined as the ratio of local to total friction velocity is introduced in the $u_{* t}$ parameterization of Shao and Lu [2000]:

$$
u_{* t}^{2}=A_{N}\left(\left(\rho_{p}-\rho\right) g \mu_{1} / \rho+\gamma /\left(\rho \mu_{1}\right)\right) / f_{\text {eff }},
$$

where $A_{N}=0.0123, \gamma=3 \times 10^{-4} \mathrm{~kg} \mathrm{~s}^{-2}$, and $f_{\text {eff }}=1-\log \left(z_{0 p} / z_{0}\right) / \log \left(0.35\left(0.1 / z_{0}\right)^{0.8}\right)$ with $z_{0 p}=\mu_{1} / 30$.

To estimate the impact of vegetation on sand erosion, the sand erosion reduction rate $r_{\text {erod }}$ (in percentage) is deduced by comparing the total saltation flux obtained over a vegetated surface $\left\langle G_{\text {tot }}\right\rangle_{t x y}$ with the equivalent one (with the same wind condition, i.e., same $u_{* s b}$ ) obtained over a bare sand $\left\langle G_{\text {totb }}\right\rangle_{t x y}$ :

$$
r_{\text {erod }}=100\left(\left\langle G_{\text {totb }}\right\rangle_{t x y}-\left\langle G_{\text {tot }}\right\rangle_{t x y}\right) /\left\langle G_{\text {totb }}\right\rangle_{t x y} .
$$

In the above equation, $\left\langle G_{\text {totb }}\right\rangle_{t x y}$ is deduced from a predictive equation similar to Lettau and Lettau's [1978] but fitted with the total saltation fluxes obtained by Du2013 over a bare sand (see their Figure 8):

$$
\left\langle G_{t o t b}\right\rangle_{t x y}=c \sqrt{\mu_{1} / D} \rho u_{* s b}^{3}\left(1-u_{* t} / u_{* s b}\right) / g
$$

where $\left\langle G_{\text {totb }}\right\rangle_{t x y}$ is in kilogram per meter per second, $D=250 \mu \mathrm{m}$, and $c=1.8$.

\section{Results}

\subsection{Flow Dynamic}

Figure 3 shows the time average wind velocity $\langle V\rangle_{t}$ field in the $x-y$ plane at $0.1 \mathrm{~m}$ height, without saltating particles, for cases B1 to B4. The wind velocity is normalized by the space-time average wind velocity $\langle V\rangle_{t x y}$ at the same height. Similarly, Figure 4a shows $\langle V\rangle_{t} /\langle V\rangle_{t x y}$ at the same height for cases T1 and T2. This $0.1 \mathrm{~m}$ 

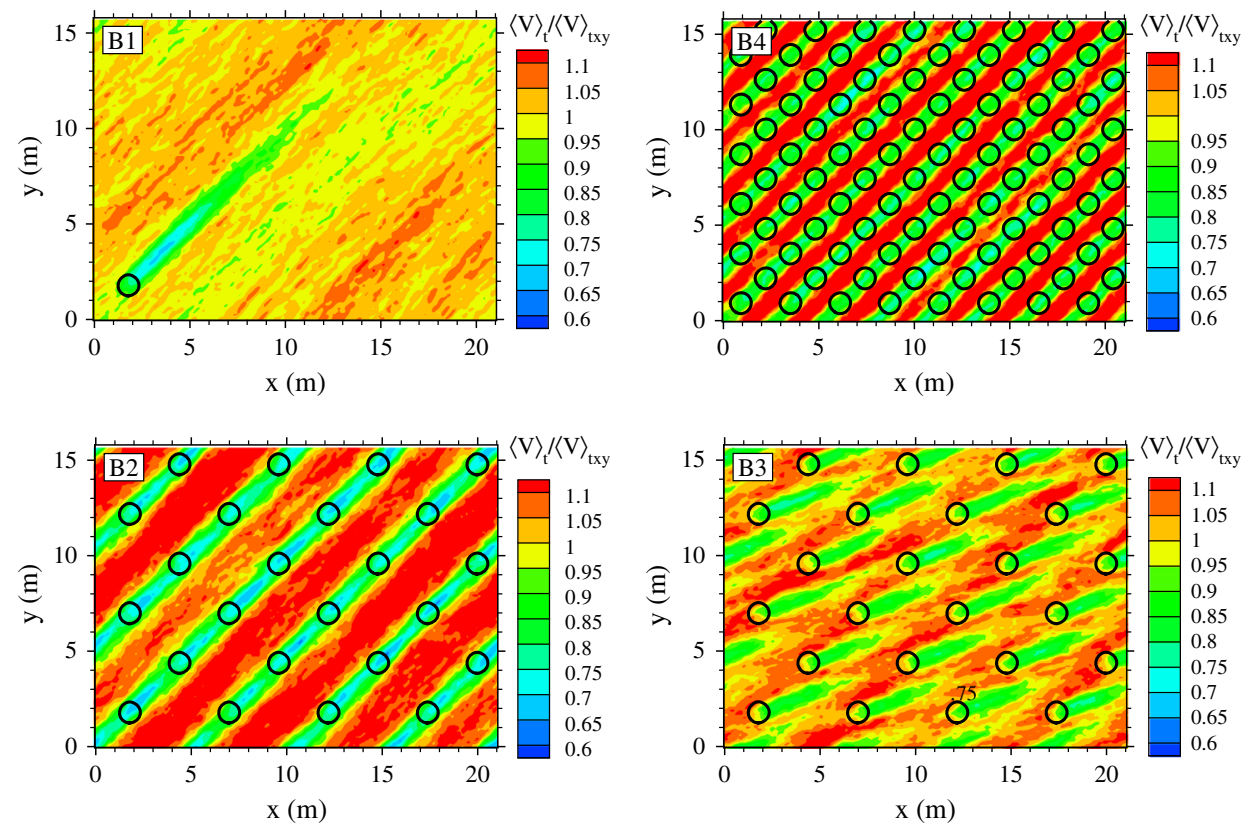

Figure 3. Time average wind velocity $\langle V\rangle_{t}$ field simulated by the model at $0.1 \mathrm{~m}$ height without saltating particles in shrub cases. $\langle V\rangle_{t}$ is normalized by the space-time average wind velocity $\langle V\rangle_{t x y}$ at the same height. The case B2 corresponds to the simulation with $u_{* s b}=$ $0.90 \mathrm{~m} \mathrm{~s}^{-1}$. The solid black circles represent the shrubs.

height corresponds roughly to the lower half of the saltation layer, where the wind intercepts the bases of the shrubs and the trunks of the trees. Additionally, Figure $4 b$ shows $\langle V\rangle_{t} /\langle V\rangle_{t x y}$ in a vertical tree-row cross section for cases $\mathrm{T} 1$ and $\mathrm{T} 2$.

For the sparsest cases, B1 and T1, well-defined wake zones form in the lee of vegetation elements where the wind velocity is reduced but not sufficiently to observe a recirculation region. The distance between vegetation elements in the mean wind direction is long enough for the flow to recover to its upwind state. The lengths of the wake zone defined as the distance for the flow to recover $95 \%$ of its upwind value are about $24 h$ and $23 h$ (where $h$ is the plant height) behind the shrub and tree of cases B1 and T1, respectively. In T1, this length has been estimated knowing the periodicity of the lateral boundary conditions. Following the well-known classification of flow regimes as isolated roughness, wake interference, or skimming flows [Lee and Soliman, 1977; Wolfe and Nickling, 1993], cases B1 and T1 correspond to an isolated-roughness flow. The form of the reduced velocity regions in the lee of the plants differs between shrubs and trees as a consequence of their different shapes. In the vertical cross section (Figure 4b), these wake zones disperse downward away from the tree. On the trunk lateral sides, slightly downwind, a zone of high wind velocity is simulated, resulting from the flow skirting the trunk and the tree crown. Leenders et al. [2007] also observed a wind flow acceleration near the surface around their trees in the Sahelian zone of Burkina Faso. This general flow behavior around individual trees is consistent with numerical observations of Gross [1987].

With increasing vegetation cover, the flow has less distance between successive elements to recover to its upwind state. Consequently, wake zones start to overlap in cases B2 and T2, corresponding to a wake interference flow regime. They totally interconnect in the row region of case B4, corresponding to a skimming flow regime. In case B3, wake regions still appear well defined, corresponding to an isolated-roughness flow regime. Interestingly, a difference of wind direction modifies substantially the wind patterns between cases B2 and B3. This is explained by the difference of distance $L$ between successive shrubs in the mean wind direction, $13.7 h$ in B3 and only $6.2 h$ in B2 (Table 1 ). In cases B2 and B4, the flow is well aligned with shrub rows. Two distinct regions appear, the region under the shrub influence with lower wind speed and the region weakly affected by shrubs with high wind speed. This latter region is comparable to the "streets" of bare soil observed in the mesquite landscape of the Chihuahuan desert by Okin and Gillette [2001]. The case B2 exhibits the highest wind velocity variability between the row and interrow regions. In case T2, the flow is not perfectly aligned with tree rows, the wind velocity being higher on the windward side than on the 
(a) Horizontal section
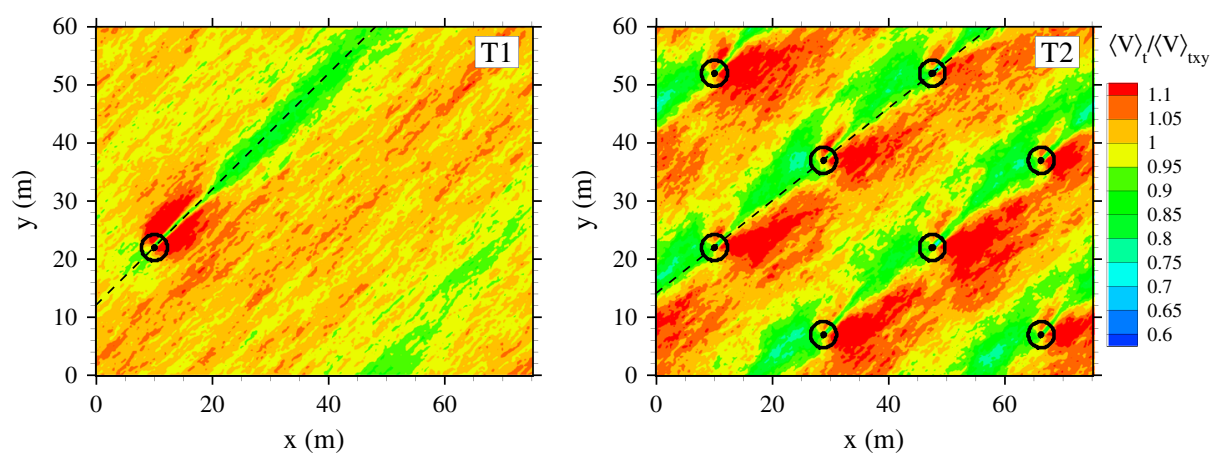

(b) Vertical section
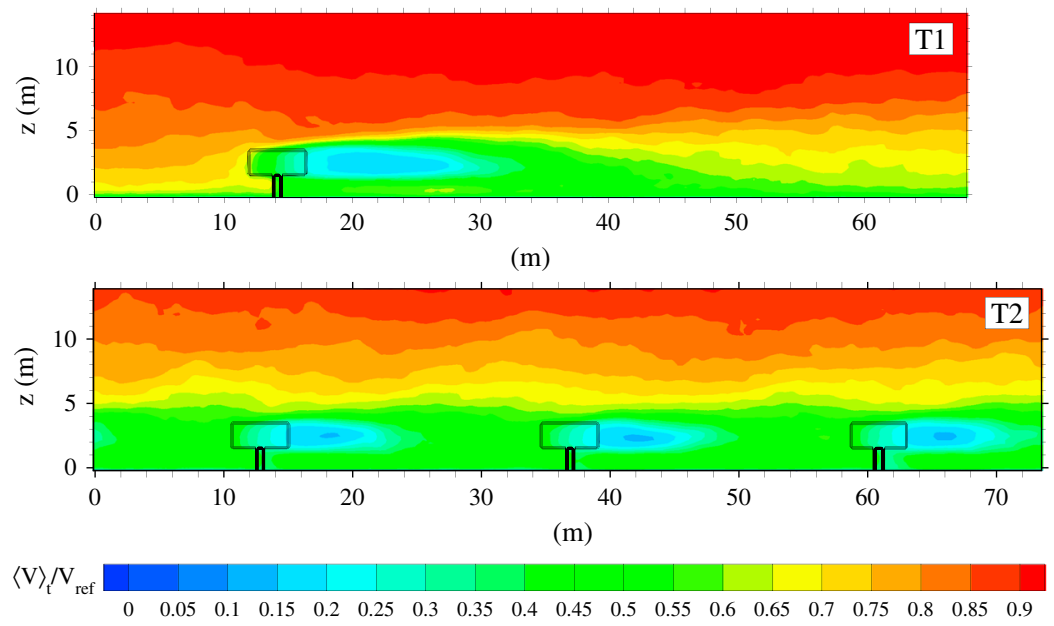

Figure 4. (a) Time average wind velocity $\langle V\rangle_{t}$ field simulated by the model at $0.1 \mathrm{~m}$ height without saltating particles in tree cases. $\langle V\rangle_{t}$ is normalized by the space-time average wind velocity $\langle V\rangle_{t x y}$ at the same height. The solid black circles represent the tree crowns. (b) Time average wind velocity $\langle V\rangle_{t}$ field normalized by the reference mean wind velocity $V_{\text {ref }}$ at $20 \mathrm{~m}$ height, in a vertical tree-row cross section corresponding to the dashed line shown in Figures $4 \mathrm{a}$. The solid black lines delimit the trees.

leeward side of the row, as a consequence of the subtle difference between the tree row orientation and the mean wind direction, $38.7^{\circ}$ and $45.0^{\circ}$ relative to the $x$ axis, respectively.

Figures $5 \mathrm{a}$ and $5 \mathrm{~b}$ present the normalized, space-time average wind velocity $\langle V\rangle_{t x y}$ and momentum flux $\tau_{m}\left(=-\left(\left\langle u^{\prime} w^{\prime}\right\rangle_{t x y}^{2}+\left\langle v^{\prime} w^{\prime}\right\rangle_{t x y}^{2}\right)^{0.5}\right)$ profiles obtained without (dashed lines) and with (solid lines) saltating particles, for shrub and tree cases, respectively. Above vegetation, the flow responds to a constant flux layer where the velocity profiles exhibit a logarithmic form and the momentum flux profiles are constant. The flow saltation friction velocity $u_{* s v}$ is deduced from the momentum flux, at $z=2 \mathrm{~m}$ for shrub cases and at $20 \mathrm{~m}$ for tree cases, such as $u_{* s v}^{2}=\left|\tau_{m}\right|$. The saltation roughness length of the vegetated surface $z_{0 s v}$ is deduced from the logarithmic form of the velocity profile, $\langle V\rangle_{t x y}=\left(u_{* s v} / \kappa\right) \log \left(\left(z-d_{s v}\right) / z_{\text {osv }}\right)$, where $\kappa=0.40$ is the Von Karman constant. In the presence of vegetation, the decrease of wind velocity and momentum flux near the surface is enhanced with increasing vegetation cover as vegetation extracts momentum from the flow. For the densest cases, B4 and T2, statistical wind profiles exhibit the same main characteristics as profiles usually observed in continuous vegetated canopies: a strong vertical shear of the mean streamwise velocity at the top of vegetation, associated with an inflection point, and a rapid decrease of the momentum flux within the canopy [e.g., Raupach et al., 1996]. In presence of particles, $\langle V\rangle_{t x y}$ exhibits a sharper decrease near the surface than without particles for bare sands and low shrub covers (BO, B1, B2, and T0), and the momentum flux is enhanced throughout the domain. With larger shrub and tree covers (B3, B4, T1, and T2), wind profiles show no differences for cases with and without particles. This is explained by the negligible momentum extracted by particles from the flow compared to the momentum extracted by the vegetation. The friction 
(a) Shrub cases

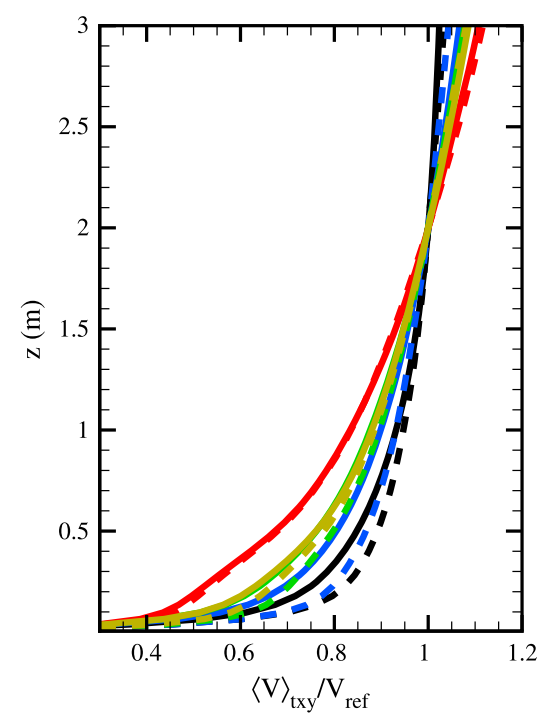

without particles

- - - - B B

$\boldsymbol{z}-\boldsymbol{z} \cdot \mathrm{B} 1$

$-\tilde{E}=-\mathrm{B} 2$

$\underline{-}-\boldsymbol{z}, \mathrm{B} 3$

$=--=\cdot \mathrm{B} 4$

(b) Tree cases

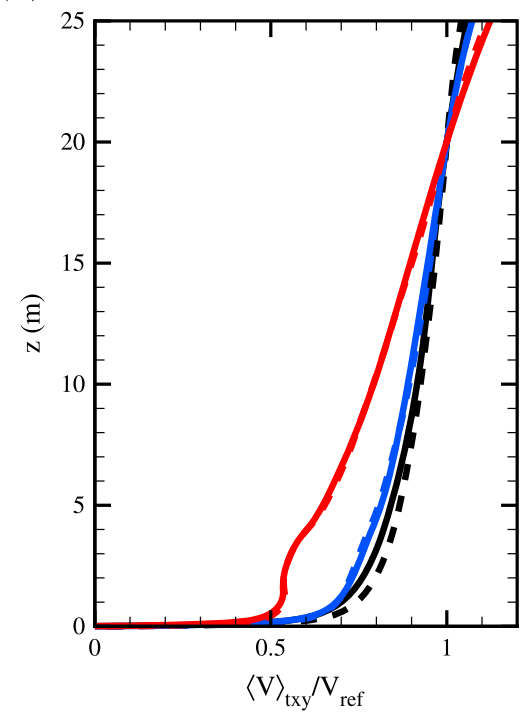

without particles

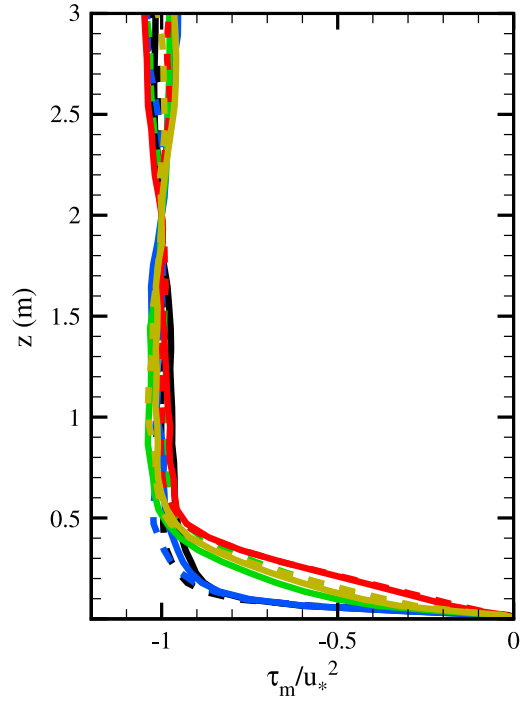

with particles
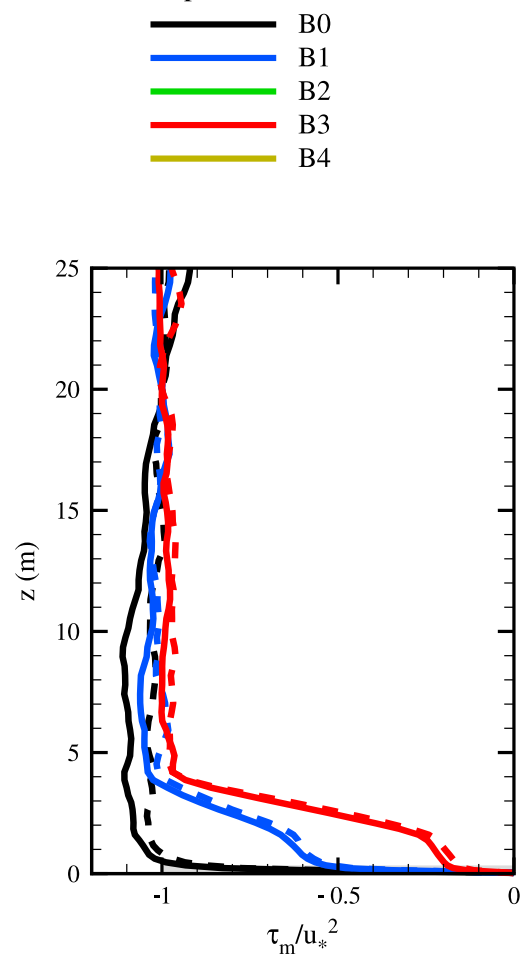

with particles

-2--2. T0

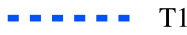

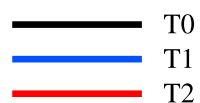

Figure 5. Vertical profiles of the mean streamwise wind velocity $\langle V\rangle_{x y}$ and momentum flux $\tau_{m}\left(=-\left(\left\langle u^{\prime} w^{\prime}\right\rangle_{t x y}^{2}+\left\langle v^{\prime} w^{\prime}\right\rangle_{t x y}^{2}\right)^{0.5}\right)$ in (a) shrub and (b) tree cases, without (dashed lines) and with (solid lines) particles. Both variables are normalized by the reference wind velocity $V_{\text {ref }}$ and the friction velocity $u_{*}$ deduced at $2 \mathrm{~m}$ and $20 \mathrm{~m}$ height in shrub and tree cases, respectively. Cases B0 and B2 correspond to simulations with $u_{* s b}=0.54$ and $0.90 \mathrm{~m} \mathrm{~s}^{-1}$, respectively. 


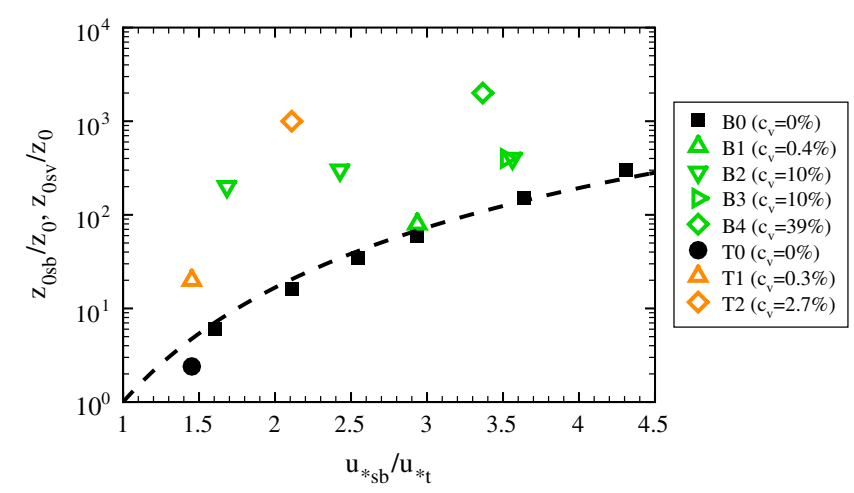

Figure 6. Saltation roughness lengths over bare $\left(z_{\text {oss }}\right)$ and vegetated $\left(z_{\text {osv }}\right)$ surfaces as a function of the saltation friction velocity over an equivalent bare sand $u_{* s,}$, deduced from all simulated cases. Roughness lengths are normalized by the ground roughness length $\left(z_{0}\right)$, and $u_{* s b}$ is normalized by the threshold friction velocity $u_{* t}$. The dashed black line fits dots of the bare sand case BO $\left(z_{0 s b} / z_{0}=\right.$ $\left(A u_{* s b}^{2} / 2 g\right)^{1-r} z_{0}^{r-1}$ with $r=u_{* t} / u_{* s b}$ and $\left.A=0.21\right)$.

velocity above the vegetation and the roughness length of the vegetated surface should therefore weakly change with saltation, and the roughness length should depend lightly on the wind conditions (i.e., $u_{* s b v}$ ).

Figure 6 presents the saltation roughness lengths ( $z_{\text {osb }}$ for bare sand and $z_{\text {osv }}$ for vegetated surface), normalized by the ground surface roughness length $z_{0}$, as a function of $u_{* s b}$ normalized by its threshold value $u_{* t}$. Despite the difference of mesh resolution and surface roughness length between bare sand cases B0 and TO, $z_{0 s b} / z_{0}$ obtained in case T0 is in close agreement with, although slightly lower than, the relationship between $z_{0 s b} / z_{0}$ and $u_{* s b} / u_{* t}$ obtained in Du2013 for bare sand (equation (7)). As expected, $z_{\text {osv }}$ increases with vegetation cover and is higher for tree than for shrub cases for similar vegetation cover. For the same vegetation configuration (B3), $z_{\text {os }}$ increases only slightly with increasing wind condition, confirming that the momentum extracted by particles is negligible compared to that extracted by vegetation.

\subsection{Sediment Transport}

Figures $7 \mathrm{a}$ and $7 \mathrm{~b}$ present an instantaneous view of the vertically integrated particle concentration field $C_{p}$ (number of particles per $\mathrm{m}^{2}$ ) normalized by its maximum value $C_{p \text { max }}$, in the horizontal section $x-y$, for shrub (B1 to B4) and tree (T1 and T2) cases, respectively. Elongated patterns of high sand concentration in the mean wind direction, known as aeolian streamers [Baas and Sherman, 2005; Du2013], are present in shrub and tree cases, surrounded by regions with low concentration. Streamers present in tree cases have similar sizes as in shrub cases with low vegetation cover. However, for the densest shrub case (B4), streamer width appears larger and scales with the interrow width. Calling these latter sand structures "streamers" may be inaccurate as they remain channelized within the interrow region without meandering much. Since aeolian streamers are a visual footprint of past turbulent eddies propagating in the surface boundary layer [Du2013], flow structures of the size of shrub or interrow width are certainly driving saltating particles in the interrow region of case B4. In case T2, streamers do not appear as well aligned with the mean wind direction as in $\mathrm{T} 1$ and shrub cases. This may be related to the presence of larger flow structures, scaling with individual trees and skirting around trees. In shrub cases, although intermittent high concentration clouds propagate from the interrow to the row regions, the sand concentration appears lower in the row regions because of the lower wind velocity (Figure 3 ) and the trapping of sand particles by shrubs. This distinction between row and interrow regions is less visible for wind oriented at $22.5^{\circ}$ (B3) than at $45^{\circ}$ (B2) because the distance between successive shrubs, $L / h$, is larger in B3 (Table 1 ), allowing the flow to recover between successive shrubs. In tree cases, the row and interrow regions are imperceptible from the instantaneous sand concentration field as the wind reduction near the surface is spread over a larger area than in shrub cases.

Figures $8 \mathrm{a}$ and $8 \mathrm{~b}$ show for shrub and tree cases, respectively, the vertical profiles of the mean horizontal mass flux $\langle G\rangle_{t x y}\left(\mathrm{~g} \mathrm{~cm}^{-2} \mathrm{~s}^{-1}\right)$ normalized by the total saltation flux $\left\langle G_{\text {tot }}\right\rangle_{t x y}\left(\mathrm{~g} \mathrm{~cm}^{-1} \mathrm{~s}^{-1}\right)$ and by the saltation layer height $z_{m}$ (see the next paragraph for a definition). For bare sand cases (B0 and T0), $\langle G\rangle_{t x y}$ decreases exponentially with height as previously observed experimentally [Nalpanis et al., 1993; Greeley et al., 1996; Rasmussen and Sorensen, 2008] and numerically [Kok and Renno, 2009; Du2013]. With vegetation, $\langle G\rangle_{t x y}$ decreases exponentially only near the surface. In the upper saltation layer and above, this decrease is much lower as the particle concentration at this level is larger than in bare sand cases. This feature is enhanced 
(a) Shrub cases
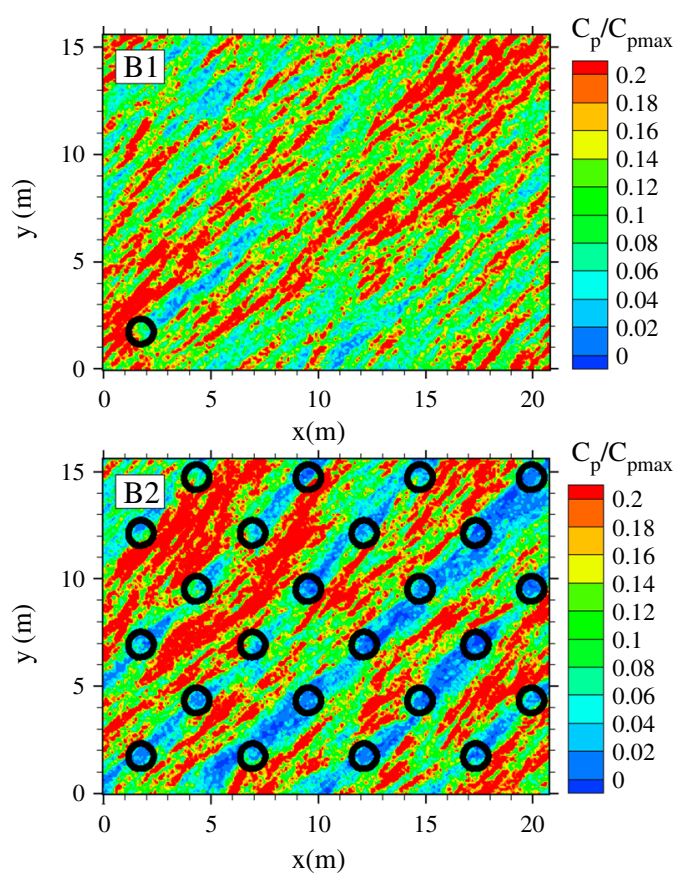

(b) Tree cases

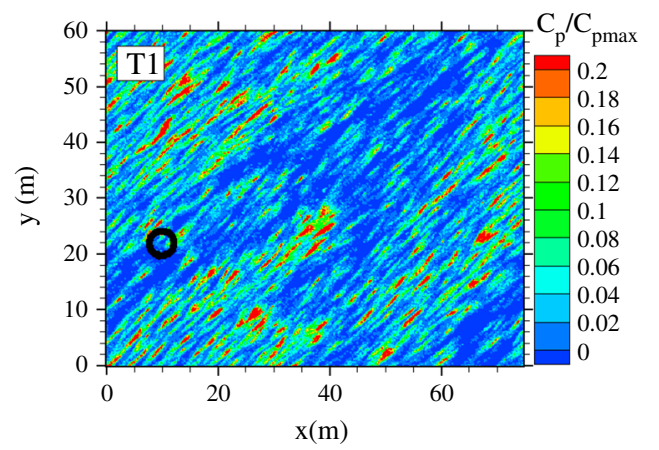

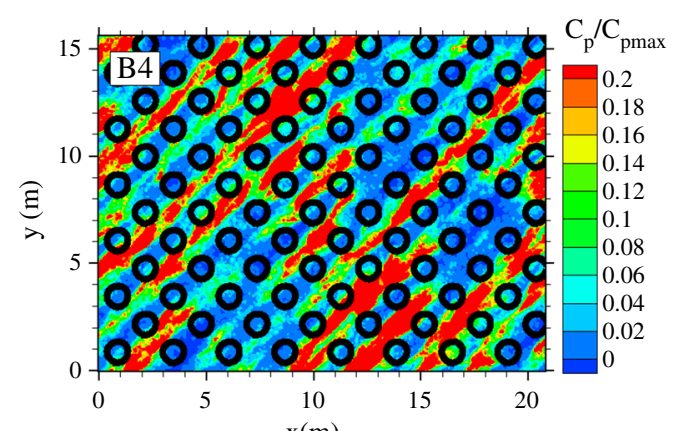
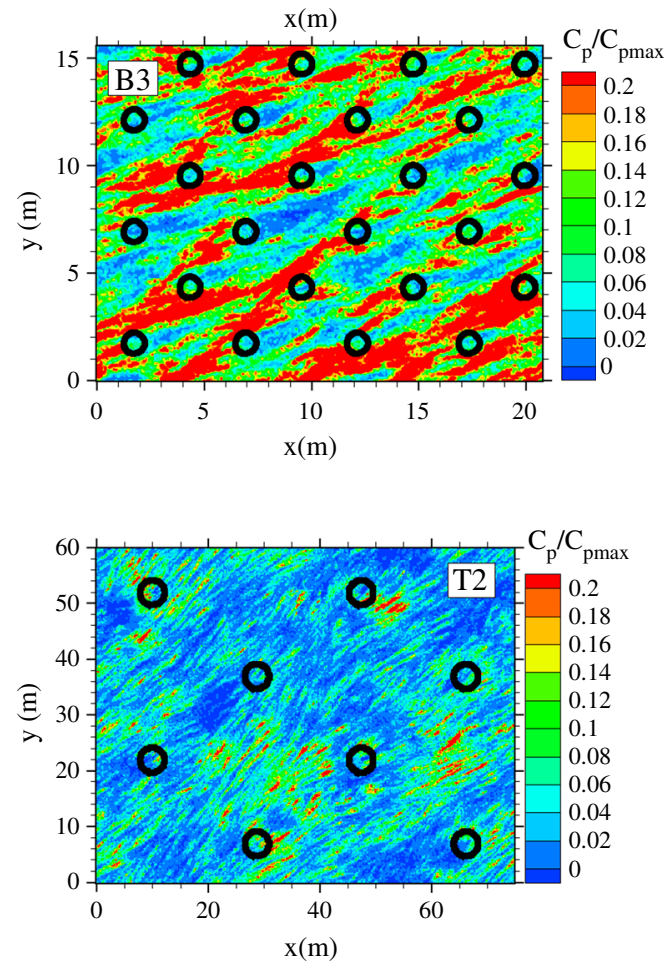

Figure 7. Snapshot of horizontal cross section $(x-y)$ of the vertically integrated sand concentration $C_{p}$ normalized by its maximum value $C_{p \max }$ for (a) shrub and (b) tree cases. The case B2 corresponds to the simulation with $u_{* s b}=0.90 \mathrm{~m} \mathrm{~s}^{-1}$. The solid black circles represent the shrubs or the tree crowns.

(a) Shrub cases

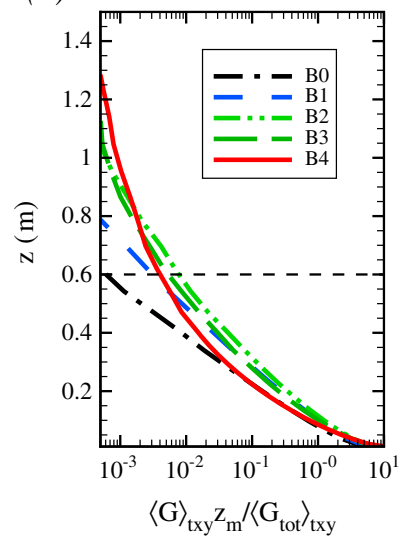

(b) Trees cases

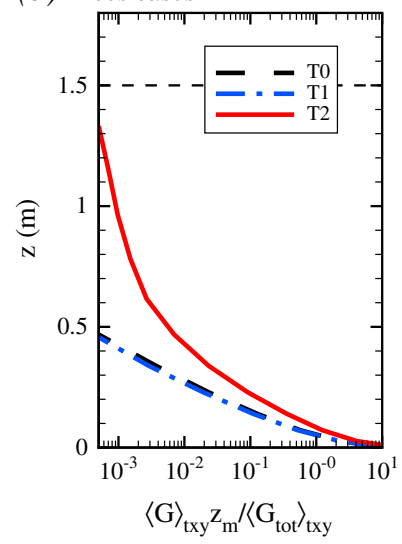

Figure 8. Vertical profiles of the mean saltation flux $\langle G\rangle_{t x y}\left(\mathrm{~g} \mathrm{~cm}^{-2} \mathrm{~s}^{-1}\right)$ normalized by the total saltation flux $\left\langle G_{\text {tot }}\right\rangle_{t x y}\left(\mathrm{~g} \mathrm{~cm}^{-1} \mathrm{~s}^{-1}\right)$ and by the saltation layer height $Z_{m}$, for (a) shrub and (b) tree cases. Cases B0 and B2 correspond to simulations with $u_{* s b}=0.54$ and $0.90 \mathrm{~m} \mathrm{~s}^{-1}$, respectively. The dashed lines represent the shrub top (Figure 8a) and the lower tree crown level (Figure 8b). 


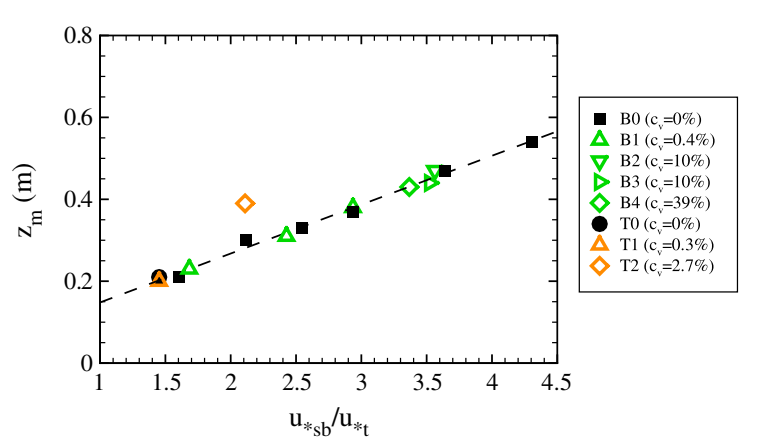

Figure 9. Saltation height $z_{m}$ as a function of the saltation friction velocity over an equivalent bare sand $u_{* s b}$, normalized by the threshold friction velocity $u_{* t}$, deduced from all simulated cases. The dashed black line fits dots of the bare sand case B0 $\left(z_{m}=\right.$ $\left.0.119 u_{* s b} / u_{* t}+0.029\right)$.

with vegetation cover and stronger in tree cases. The presence of larger flow structures scaling with plants is probably responsible for the upward transport of saltating particles. However, this upward transport involves only a very small amount of particles and consequently a small portion of $\left\langle G_{\text {tot }}\right\rangle_{t x y}$. In T0 and T1 cases, concentration profiles are almost identical.

The saltation layer height $z_{m}$ is deduced here from the mass flux profile because the momentum flux is not constant above the saltation layer with the presence of vegetation. Hence, $z_{m}$ is deduced as the height below which $99.5 \%$ of the total mass flux $\left\langle G_{\text {tot }}\right\rangle_{t x y}$ occurs. Figure 9 presents for all cases, $z_{m}$ as a function of $u_{* s b} / u_{* t}$. As observed in Du2013, $z_{m}$ increases linearly with $u_{* s b} / u_{* t}$ for bare sand. More surprisingly, $z_{m}$ values do not depart much from a linear relationship in the presence of vegetation; $z_{m}$ is only slightly larger in case T2. Although vertical saltation flux profiles of vegetated cases have different shapes than those over bare sands, these differences concern only a small number of particles. Consequently, the saltation layer height appears (1) weakly impacted by the presence of shrubs whatever their distribution, at least for the characteristics studied here, and (2) slightly larger in presence of trees for the densest configuration case.

\subsection{Sand Erosion Patterns}

The spatial distribution of the time average budget of sand erosion $\left\langle E_{s}\right\rangle_{t^{\prime}}$ normalized by its maximum value, is presented in Figures 10a and 10b, in a $x$-y plane, for shrub (B1 to B4) and tree (T1 and T2) cases. $\left\langle E_{s}\right\rangle_{t}$ is the difference between the number of particles emitted per square meter and the number of particles deposited on sand bed and on vegetation. Hence, negative values of $\left\langle E_{s}\right\rangle_{t}$ correspond to sand accumulation and positive values to erosion. Although wind conditions differ between cases, the comparison of the magnitude of accumulative and erosive regions is possible since $\left\langle E_{s}\right\rangle_{t}$ is normalized and since the sand erosion reduction rate due to vegetation is weakly sensitive to wind condition (see section 4.2).

In shrub cases, distinct erosion patterns related to the vegetation distribution are visible. They correspond (1) to accumulation on the shrubs themselves because of sand trapping, (2) to sand accumulation on the lee of shrubs where the wind velocity is reduced as a consequence of vegetation wake effect (section 3.1), and (3) to erosion in the interrow region where the wind velocity is higher. The accumulation on shrubs relative to the maximum erosion is higher in case B1 and lower in case B4. For the two cases with the same plant configuration (B2 and B3), the relative accumulation on shrubs is the largest in B3 where the distance between successive shrubs in the mean wind direction, $L / h$, is the longest. This means that the relative deposition on shrubs decreases with $L / h$. The amplitudes of sand accumulation and (sand erosion) on the lee of shrubs (in the interrow), relative to the maximum erosion, do not vary much. Accumulative regions overlap downwind of shrubs in cases B2 and B3 and appear longer in the lower vegetation cover case B1 than in B3. The relative sand erosion is slightly larger on shrub lateral sides of case B4.

In tree cases, erosion is observed on the lateral side of the trunks and upwind where the wind velocity is higher because of the flow skirting around the trees. Sand accumulates on the lee of trees over a region scaling with the tree size. Unlike in shrub cases, (1) particle are not trapped by trees as the saltation layer is located below the tree crowns and (2) no erosion is observed in the interrow region. The spatial variability of erosion is not as marked in tree cases as in shrub cases. Our explanation is that shrubs have a local impact by trapping particles and reducing locally the wind velocity while trees have a larger scale of influence by reducing the wind velocity in the lower atmospheric surface layer. 

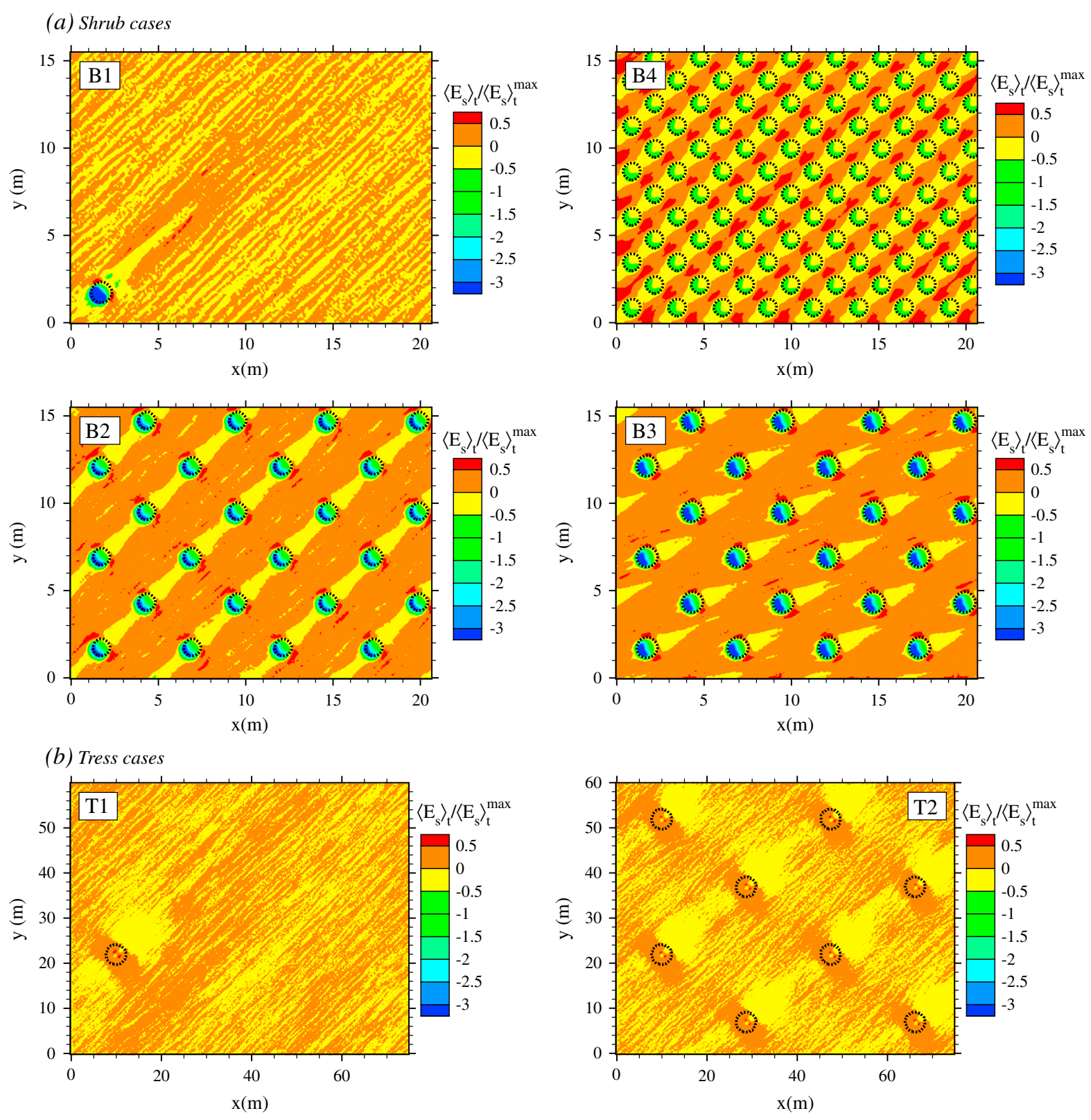

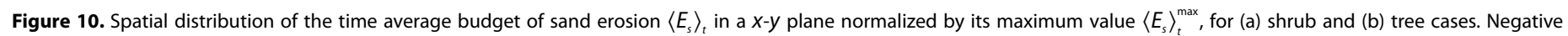

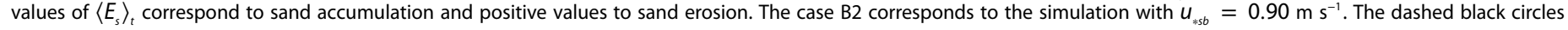
represent the shrubs or the tree crowns. 


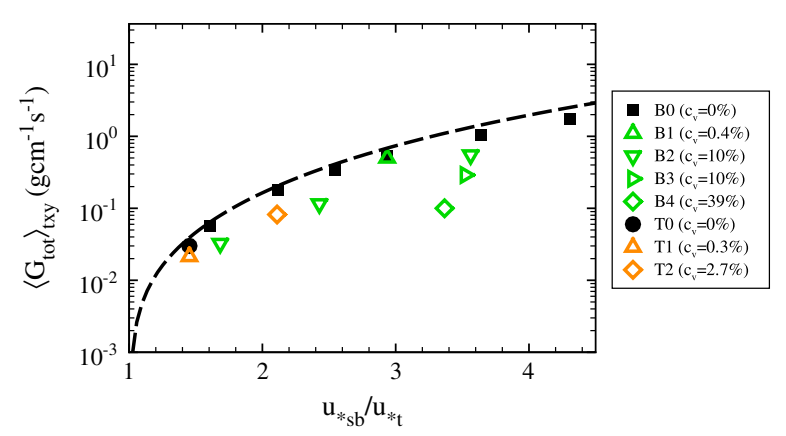

Figure 11. Total saltation flux $\left\langle G_{\text {tot }}\right\rangle_{t x y}$ as a function of the saltation friction velocity over an equivalent bare sand $u_{* s b}$ normalized by the threshold friction velocity $u_{* t}$, deduced from all simulated cases. The dashed black line fits dots of the bare sand case $B 0\left(\left\langle G_{t o t}\right\rangle_{t x y}=\right.$ $c \sqrt{\left\langle d_{p}\right\rangle / D \rho u_{* s b}^{3}}\left(1-u_{* t} / u_{* s b}\right) / g$ with $D=250 \mu \mathrm{m}$ and $c=1.8$ for $\left\langle G_{\text {tot }}\right\rangle_{t x y}$ in kilogram per meter per second).

As for the saltation roughness length, $\left\langle G_{\text {tot }}\right\rangle_{\text {txy }}$ of case T0 is in close agreement with the relationship obtained by Du2013 between $\left\langle G_{\text {tot }}\right\rangle_{t x y}$ and $u_{* s b} / u_{* t}$ for bare sand. Dots related to vegetated cases are located below this curve meaning that the presence of vegetation reduces sand erosion. For some specific configurations with sparse vegetation, Musick et al. [1996] and Burri et al. [2011] observed that the presence of vegetation elements increases sand erosion. They explained this feature by the formation of high wind speed regions, as observed in our simulation, that increase erosion without being balanced by a decrease of erosion behind plants. This enhancement of erosion was not observed here. In case $B 2,\left\langle G_{\text {tot }}\right\rangle_{\text {txy }}$ appears to increase with $u_{* s b} / u_{* t}$ as observed over bare sand but with a lower magnitude, corresponding to a sand erosion reduction of about $52 \%$. This value slightly changes with wind condition but without showing a clear tendency (Table 1). The erosion reduction increases with vegetation cover. For the same vegetation cover, the magnitude of $r_{\text {erod }}$ differs between shrubs and trees. A tree cover of $0.3 \%$ reduces erosion by $77 \%$, while for the same cover of shrubs $(0.4 \%)$ the erosion reduction is only $8 \%$. To reach a reduction of $77 \%$, the shrub cover has to be between $10 \%$ and $39 \%$. Finally, for the same shrub arrangement and cover, the erosion reduction is on average $52 \%$ in case B2 and $72 \%$ in case B3, meaning that variations in wind direction can impact significantly the sand erosion.

\section{Discussion}

In the previous section, we identified flow and sand erosion patterns related to vegetation characteristics and quantified the saltation flux reduction induced by the presence of the vegetation. In this section, we discuss these findings by comparing them to observations reported in the literature and with simple predictive models of erosion reduction associated with vegetation characteristics.

\subsection{Wind Flow and Sand Erosion Patterns}

The flow regimes (isolated-roughness, wake interference and skimming flows) of each of the vegetation configurations have been identified in section 3.1 following the degree of interaction between wake zones developing behind vegetation elements. Lee and Soliman [1977] established a correspondence between these flow regimes and the concentration of surface roughness elements. This concentration is defined by the distance between successive plants in the mean wind direction $L / h$, the vegetation cover $c_{v}$, and the roughness density $\lambda$ (the total frontal area of all plants divided by the total area) (Table 1). The criteria of Lee and Soliman [1977], based on these vegetation characteristics, lead to the same flow regimes as the ones deduced from our model, except for cases B2 and T2 that would be classified as isolated flow instead of wake interference flow.

The sand erosion patterns observed in all vegetated cases are related to wind field patterns and consequently to the flow regimes. This is consistent with the wind-tunnel observations of Sutton and McKenna-Neuman [2008a, 2008b] who related the spatial variations of surface shear stress and turbulent fluctuations to sediment entrainment near isolated, solid roughness elements. Sand accumulation regions behind vegetation elements appear correlated with the wake zones identified in section 3.1. This means that vegetation protects the surface on its lee side from saltation impacts and consequently from particle ejections. As a consequence, flow regimes can be identified from the degree of interaction between sand 


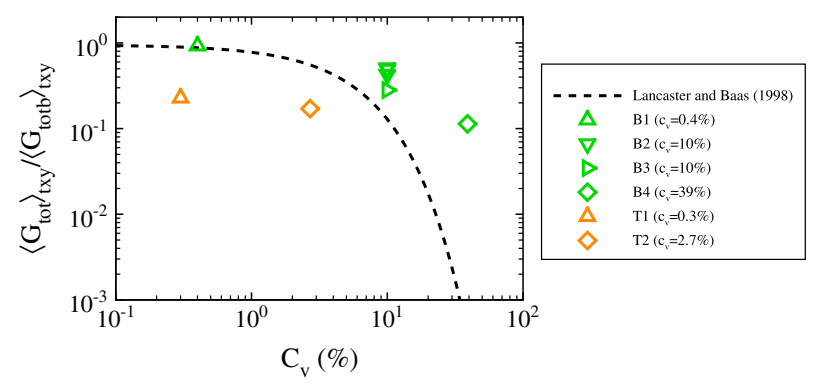

Figure 12. Comparison between the present model (dots) and Lancaster and Baas's [1998] predictive equation (dashed line) of the total saltation flux $\left\langle G_{\text {tot }}\right\rangle_{t x y}$ normalized by its equivalent value over a bare sand $\left\langle G_{t o t b}\right\rangle_{t x y}$ as a function of the vegetation cover $C_{v}$, for all vegetated cases.

accumulation regions developing behind plants. This was done by Burri et al. [2011] from their wind-tunnel experiment.

In shrub cases, sand accumulation in the lee of plants as well as the degree of overlapping between the accumulations following the vegetation distribution, match very well with the patterns observed by Burri et al. [2011] on a regular arrangement of small plants and with the formation of sand tails observed by Sutton and McKenna-Neuman [2008b] in the lee of solid elements. However, contrary to Sutton and McKenna-Neuman [2008b], we do not observe enhanced erosion in the far wake of shrubs. The role of small vegetation in initiating accumulation regions and in initiating the formation of aeolian dunes is well known in semiarid and coastal environments. For example, Nebkha dunes are known as small ovoid dunes developing behind small shrubs, resulting from sand accumulation on the shrub itself and on its lee side [e.g., Danin, 1996; Nield and Baas, 2008].

In tree cases, higher sand erosion around tree trunks (section 3.3) was observed by Leenders et al. [2007] in the Sahelian zone of Burkina Faso and on the lateral side of solid roughness elements by Sutton and McKenna-Neuman [2008b] and McKenna-Neuman et al. [2013]. This is explained by the faster wind velocity around the trunk. A visualization of the spatial distribution of the saltation flux (not shown) exhibits the same patterns as those observed from the erosion budget, with a spatial variability of about $50 \%$ of the mean saltation flux. Saltation flux measurements performed by Labiadh et al. [2013] on a Tunisian orchard similar to case T2 did not identify a spatial variability of the flux between olive trees larger than the precision of the measurements. They obtained a spatial variability of about $17 \%$ of the mean flux. This value could be explained by the high variability of the wind direction during Labiadh et al.'s field erosion event, contributing to smoother sand erosion patterns. Their standard deviation of wind direction was $95^{\circ}$ while in our simulation the mean wind condition was constant, leading to a standard deviation of about $10^{\circ}$.

In conclusion, the sand erosion patterns simulated in shrub and tree cases are qualitatively consistent with previous wind-tunnel and field observations. The regularity of these patterns may be smeared in reality as a consequence of large scale wind direction fluctuations during erosion events. Although our model neglects the deformation of the sand bed during an erosion event, it identifies the possible location of dune formation from erosion patterns. Specific models simulating the dynamics of dune formation in the presence of vegetation have been developed based on cellular automation algorithm [Nield and Baas, 2008]. While our model focuses on sand transport for individual erosion events, models of dune formation focus on the long-term sand surface dynamic by simplifying the sand transport. Our approach cannot simulate dune formation because of computational limitations, but it could improve the sand transport component in existing dune models.

\subsection{Saltation Flux Reduction}

As stated in section 1, Lancaster and Baas [1998] proposed a relationship between sand erosion reduction and vegetation cover. The equation was deduced from measurements conducted at Owens Lake in California with a cover of salt grass of about $0.10 \mathrm{~m}$ height. Figure 12 presents the total saltation flux $\left\langle G_{\text {tot }}\right\rangle_{\text {txy }}$ normalized by its equivalent value over bare sand $\left\langle G_{t o t b}\right\rangle_{t x y}$ as a function of the vegetation cover $c_{v}$. On the same figure is shown the relationship proposed by Lancaster and Baas [1998] (dashed line).

For shrub cases, our model predicts less erosion reduction than the relationship of Lancaster and Baas [1998]. Furthermore, our model is sensitive to the wind direction relative to the plant distribution. For the 
same vegetated surface (cases B2 and B3), the erosion reduction predicted by our model increases from $52 \%$ to $72 \%$ for a wind direction changing from $45^{\circ}$ to $22.5^{\circ}$. An additional simulation with a mean wind direction of $0^{\circ}$ showed an erosion reduction of $100 \%$, as the saltation process ceased few minutes after its initiation (result not shown). The lower values of erosion reduction obtained from our model could be explained by the regular arrangement of shrubs relative to the main wind directions in cases B1, B2, and B4. In case B3, where the wind direction is not as well aligned with plant distribution, the erosion reduction is larger. This is consistent with field experiments where the presence of "streets" of bare soil was observed to increase the overall soil erosion in the mesquite landscape of the Chihuahuan desert [King et al., 2006; Bowker et al., 2007]. On the other hand, for a similar shrub distribution as in the present study but with different shrub characteristics and spacing, Burri et al. [2011] obtained, from their wind-tunnel experiment, a sand erosion reduction in good agreement with Lancaster and Baas's [1998] model. This could be related (1) to the $0^{\circ}$ wind direction relative to their plant distribution that gave us an erosion reduction of $100 \%$, (2) to their higher plant roughness density $\lambda$, or (3) to their bigger saltating particles (around $600 \mu \mathrm{m}$ ). In tree cases the erosion reduction predicted by our model is higher than that predicted by Lancaster and Baas's [1998] equation. Since their relationship was obtained from small plants, it may not be applicable to larger vegetation such as trees. Finally, vegetation cover may not be the best variable to characterize the impact of vegetation on sand erosion. The frontal area density may be more appropriate as it measures the momentum absorbed by the vegetation [Raupach et al., 1993]. However, sand erosion reduction as a function of the frontal area density did not show a combined relationship between shrub and tree cases (figure not shown). It is unclear how the roughness elements should be characterized to obtain, for any vegetation morphology and distribution, a unique relationship between the sand erosion reduction rate and a vegetation characteristic.

To confirm the sensitivity of erosion reduction to wind direction, and to verify that the low erosion reduction obtained from our model in shrub cases is related to our specific distribution of plants, we compare here our predictions in shrub cases B2, B3, and B4 with the ones deduced from the approach of Okin [2008] based on shear stress partitioning. Following his approach, we divided the sand bed of shrub cases into two regions: (1) the interrow region where the impact of shrubs on wind flow and saltation is neglected and the erosion is assumed equivalent to that over bare sand and (2) the row region where the ratio between the local saltation friction velocity $\left(u_{* s b}^{\text {loc }}\right)$ and the equivalent one in the absence of plants $\left(u_{* s b}\right)$ is assumed to increase exponentially downwind from the shrubs according to the measurements of Bradley and Mulhearn [1983]. The local saltation flux is then deduced from the parameterization of Shao et al. [1993] depending on $u_{* s b}^{\text {loc }} / u_{* s b}$. In Table 1, the values of the erosion reduction $r_{\text {erod }}^{*}$ obtained from this approach are compared with the values $r_{\text {erod }}$ deduced from our model. The approach of Okin [2008] exhibits the same trend as our model following vegetation cover and wind direction. The magnitude of $r_{\text {erod }}^{*}$ is similar to $r_{\text {erod }}$ in case B4 and lower in other cases, with a difference going up to $20 \%$ in case B2 with $u_{* s b}=0.62 \mathrm{~m} \mathrm{~s}^{-1}$. Predictions from Okin's approach appear lower than those from our model, which are lower than Lancaster and Baas' predictions. The fact that our model is not accounting for surface deformation as the erosion proceeds could be one of the reasons for such differences. Overall, this intercomparison confirms (1) that the vegetation distribution following the mean wind direction has a significant impact on sand erosion reduction and (2) the magnitude of sand erosion reduction is significantly different from one approach to another although our approach and that of Okin [2008] exhibit the same sensitivity to shrub distribution.

\subsection{Shrub Versus Tree}

Trees appear to be more efficient to reduce sand erosion than shrubs. Although shrubs trap saltating particles, the better efficiency of trees to reduce erosion is explained by the large-scale wind reduction induced by trees compared to the local sheltering effect of shrubs. This difference has been identified by Leenders et al. [2007] from their field experiment although they were not able to conclude on the better efficiency between trees and shrubs. They recommended using both types of vegetation to limit erosion.

From our simulations, shrubs appear subject to immersion while trees are subject to uprooting. Indeed, unlike shrubs, trees are not capable of trapping saltating particles as the height of their crowns starts well above the saltation layer. The factors responsible for sand erosion or accumulation following plant type have to be accounted for in orchard and crop management practices. For example, the alignment of the plants relative to the direction of the strongest winds and their distance relative to plant height could be considered in young crops in order to limit erosion in the interrow or to limit plant immersion. 


\section{Summary and Conclusion}

The saltation model of Du2013, coupled with a LES airflow model, has been extended to vegetated surfaces. For the first time, erosion of vegetated surfaces has been simulated accounting for the interaction between saltation processes and turbulent eddy structures of the flow. Compared to wind-tunnel or field measurements, such a model allows one (1) to have access to instantaneous wind and saltation fields at all locations in a heterogeneous environment and (2) to investigate the impact of vegetation on sand erosion for well controlled and simplified erosion events. The application of such model in some field conditions is still difficult because (1) lateral periodic conditions used for resolving accurately turbulence structures require a regular arrangement of plants, (2) large-scale wind conditions (mean direction and mean intensity) remain constant during simulated events which is not always the case in reality, (3) subgrid scale deformations of the bed surface such as sand ripples are difficult to account for, and (4) bed surface deformations by erosion are not considered. Despite these difficulties, we were able to simulate successfully sand erosion with two types of vegetation representative of semiarid areas, shrubs and trees, with various spatial distributions. The following conclusions can be drawn from this numerical study.

1. Saltation processes over vegetated surface have a limited impact on the mean statistics of the wind flow, the momentum extracted from the flow by plants being much larger than the momentum extracted by saltating particles. This result means that the friction velocity above the vegetation and the roughness length of the vegetated surface do not change with saltation, and the roughness length is weakly dependent on the wind intensity by neglecting the streamlining of plants under the wind load. Furthermore, the height of the saltation layer appears weakly impacted by the presence of vegetation; it increases linearly with wind speed as over bare sands. The presence of trees only increases slightly the depth of this layer due probably to large eddies, scaling with tree size, that lift some saltating particles.

2. Sand erosion patterns appear qualitatively consistent with previous wind-tunnel and field observations. These patterns are related to the mean surface wind field. Wake zones behind plants are associated with accumulation regions and fast wind zones to erosion regions. The degree of interaction between accumulation regions informs on the wind flow regimes (i.e., isolated-roughness, wake interference, or skimming flow regimes).

3. The presence of vegetation reduces erosion. This reduction depends not only on vegetation cover but also on plant morphology and plant distribution relative to the mean wind direction. A comparison between the present model and the model of Okin [2008] on shrub cases showed that they both exhibit the same sensitivity to shrub distribution relative to the mean wind direction, as opposed to the simple predictive equation of Lancaster and Baas [1998]. However, all approaches predict different magnitudes of erosion reduction, meaning that the level of reduction due to the presence of vegetation is still difficult to estimate accurately and needs further investigation.

Acknowledgments

We would like to thank the Center for Analysis and Prediction of Storms (CAPS) at the University of Oklahoma for providing the ARPS code. Computer simulations related to this work were performed using the Avakas cluster from MésoCentre MCIA as well as the EPHYSE cluster. Thanks are expressed to the EPHYSE computing team (Patrick Moreau, Tovo Rabemanantsoa, Guy Pracros, and Mark R. Irvine) for their help with the cluster setup and administration. We would like to thank Mark R. Irvine for his help with the parallelization of the Lagrangian model inside ARPS. Financial support from the program "PEDO COTESOF" of the Agence Nationale de la Recherche (ANR) is gratefully acknowledged. This study has been carried out in the framework of the Cluster of Excellence COTE. Finally, we thank A. Densmore, J. King, M. Raupach, D. Sherman, and one anonymous reviewer for their helpful comments.
4. Trees appear more efficient than shrubs in reducing sand erosion. Although shrubs trap saltating particles, trees induce a wind reduction at larger scale than the local sheltering effect of shrubs. Trees are more inclined to be uprooted and shrubs to be immersed. The immersion of shrubs can be limited by reducing the distance between successive shrubs along the mean wind direction.

To conclude, the present model appears to be very powerful for simulating sand erosion in heterogeneous vegetated landscapes. In the future, the model could be applied over complex terrains like desert dune fields since the Navier-Stokes equations of the airflow model are written in terrain-following coordinates [Dupont et al., 2008]. Although this model can only be used at the scale of a short erosion event because of computational time limitations, it could improve the wind transport component of models simulating dune formation in vegetated environments.

\section{References}

Almeida, M. P., J. S. Andrade, and H. J. Herrmann (2006), Aeolian transport layer, Phys. Rev. Lett., 96, 018001, doi:10.1103/ PhysRevLett.96.018001.

Anderson, R. S., and P. K. Haff (1988), Simulation of eolian saltation, Science, 241(4867), 820-823.

Anderson, R. S., and P. K. Haff (1991), Wind modification and bed response during saltation of sand in air, Acta Mech., 1, $21-51$.

Andreotti, B. (2004), A two-species model of aeolian sand transport, J. Fluid Mech., 510, 47-70.

Armbrust, D., and A. Retta (2000), Wind and sandblast damage to growing vegetation, Ann. Arid Zone, 39, $273-284$.

Aylor, D. (1982), Modeling spore dispersal in a barley crop, Agric. Meteorol., 26, 215-219.

Baas, A. C. W., and D. J. Sherman (2005), Formation and behavior of aeolian streamers, J. Geophys. Res., 110, F03011, doi:10.1029/2004JF000270. 
Bergametti, G., and D. Gillette (2010), Aeolian sediment fluxes measured over various plant/soil complexes in the Chihuahuan desert, J. Geophys. Res., 115, F03044, doi:10.1029/2009JF001543.

Bowker, G., D. Gillette, G. Bergametti, B. Marticorena, and D. Heist (2007), Sand flux simulations at a small scale over a heterogeneous mesquite area of the northern Chihuahuan desert, J. Appl. Meteorol. Climatol., 46, 1410-1422.

Bradley, E., and P. Mulhearn (1983), Development of velocity and shear-stress distributions in the wake of a porous shelter fence, J. Wind Eng. Indust. Aerodyn., 15, 145-156.

Burri, K., C. Gromke, M. Lehning, and F. Graf (2011), Aeolian sediment transport over vegetation canopies: A wind tunnel study with live plants, Aeolian Res., 3, 205-213.

Danin, A. (1996), Adaptations of Stipagrostis species to desert dunes, J. Arid. Environ., 34, 297-311.

Doorschot, J. J. J., and M. Lehning (2002), Equilibrium saltation: Mass fluxes, aerodynamic entrainment, and dependence on grain properties, Boundary-Layer Meteorol., 104, 111-130.

Dupont, S., and Y. Brunet (2008a), Influence of foliar density profile on canopy flow: A large-eddy simulation study, Agric. For. Meteorol., $148,976-990$.

Dupont, S., and Y. Brunet (2008b), Edge flow and canopy structure: A large-eddy simulation study, Boundary-Layer Meteorol., 126, 51-71. Dupont, S., and Y. Brunet (2009), Coherent structures in canopy edge flow: A large-eddy simulation study, J. Fluid Mech., 630, 93-128.

Dupont, S., Y. Brunet, and J. J. Finnigan (2008), Large-eddy simulation of turbulent flow over a forested hill: Validation and coherent structure identification, Q. J. R. Meteorolog. Soc., 134, 1911-1929.

Dupont, S., F. Gosselin, C. Py, E. de Langre, P. Hemon, and Brunet Y. (2010), Modelling waving crops using large-eddy simulation: Comparison with experiments and a linear stability analysis, J. Fluid Mech., 652, 5-44.

Dupont, S., J. M. Bonnefond, M. R. Irvine, E. Lamaud, and Y. Brunet (2011), Long-distance edge effects in a pine forest with a large and sparse trunk space: In situ and numerical experiments, Agric. Forest Meteorol., 151, 328-344.

Dupont, S., G. Bergametti, B. Marticorena, and S. Simoëns (2013), Modeling saltation intermittency, J. Geophys. Res. Atmos., 118, 1-20, doi:10.1002/jgrd.50528.

Field, J., J. Belnap, D. Breshears, J. Neff, G. Okin, J. Whicker, T. Painter, S. Ravi, M. Reheis, and R. Reynolds (2010), The ecology of dust, Front. Ecol. Environ., 8(8), 423-430.

Fryrear, D., and J. Downes (1975), Estimating seeding survival from wind erosion parameters, Trans. ASAE, 18, 888-891.

Gillette, D., and A. Pitchford (2004), Sand flux in the northern Chihuahuan desert, New Mexico, USA, and the influence of mesquite-dominated landscapes, J. Geophys. Res., 109, F04003, doi:10.1029/2003JF000031.

Greeley, R., D. G. Blumberg, and S. H. Williams (1996), Field measurements of the flux and speed of wind-blown sand, Sedimentology, 43, 41-52.

Gross, G. (1987), A numerical study of the air flow within and around a single tree, Boundary-Layer Meteorol., 40, 311-327.

Huang, J., P. Minnis, H. Yan, Y. Yi, B. Chen, L. Zhang, and J. Ayers (2010), Dust aerosol effect on semi-arid climate over Northwest China detected from A-Train satellite measurements, Atmos.Chem. Phys., 10, 6863-6872.

IPCC (2007), The Fourth Assessment Report of the Intergovernmental Panel on Climate Change, 996 pp., Cambridge Univ. Press, Cambridge, U. K., and New York.

King, J., W. Nickling, and J. Gillies (2006), Aeolian shear stress ratio measurements within mesquite-dominated landscapes of the Chihuahuan desert, New Mexico, USA, Geomorphology, 82, 229-244.

Kok, J. F., and N. O. Renno (2009), A comprehensive numerical model of steady state saltation (COMSALT), J. Geophys. Res., 114, D17204, doi:10.1029/2009JD011702.

Labiadh, M., G. Bergametti, M. Kardous, S. Perrier, N. Grand, B. Attoui, S. Sekrafi, and B. Marticorena (2013), Wind erosion over tilled surfaces in South Tunisia: Experiments and modelling, Geoderma, 202-203, 8-17.

Lancaster, N., and A. Baas (1998), Influence of vegetation cover on sand transport by wind: Field studies at Owen Lake, California, Earth Surf. Process. Landforms, 23, 69-82.

Lee, B., and B. Soliman (1977), An investigation of the forces on three dimensional bluff bodies in rough wall turbulent boundary layers, J. Fluid Eng., 99, 503-509.

Leenders, J., J. van Boxel, and G. Sterk (2007), The effect of single vegetation elements on wind speed and sediment transport in the Sahelian zone of Burkina Faso, Earth Surf. Process. Landforms, 32, 1454-1474.

Leenders, J., G. Sterk, and J. van Boxel (2011), Modelling wind-blown sediment transport around single vegetation elements, Earth Surf. Process. Landforms, 36, 1218-1229.

Legg, B. (1983), Movement of plant pathogens in the crop canopy, Phil. Trans. R. Soc. Lond. B, 302, 559-574.

Lettau, K., and H. Lettau (1978), Experimental and micro-meteorological field studies of dune migration, in Exploring the World's Driest Climate, Rep. 101, edited by H. H. Lettau and K. Lettau, pp. 110-147, Inst. for Environ. Stud., Univ. of Wisc., Madison.

Li, J., G. Okin, and L. Alvarez (2007), Quantitative effects of vegetation cover on wind erosion and soil nutrient loss in a desert grassland of southern New Mexico, USA, Biogeochemistry, 85, 317-332.

Li, X.-Y., L.-Y. Liu, and J.-H. Wang (2004), Wind tunnel simulation of aeolian sandy soil erodibility under human disturbance, Geomorphology, 59, 3-11.

Marticorena, B., and G. Bergametti (1995), Modeling the atmospheric dust cycle: 1. Design of a soil-derived dust emission scheme, J. Geophys. Res., 100(D8), 16,415-16,430.

May, K., and R. Clifford (1967), The impaction of aerosol particles on cylinders, spheres, ribbons and discs, Ann. Occup. Hyg., 10, 83-95.

McCartney, H., and B. Fitt (1985), Construction of dispersal models, in Mathematical Modelling of Crop Disease, vol. 3, edited by C. A. Gilligan, pp. 107-143, Advances in Plant Pathology.

McKenna-Neuman, C., R. Sanderson, and S. Sutton (2013), Vortex shedding and morphodynamic response of bed surfaces containing non-erodible roughness elements, Geomorphology, 198, 45-56.

Musick, H., S. Trujillo, and C. Truman (1996), Wind-tunnel modelling of the influence of vegetation structure on saltation threshold, Earth Surf. Process. Landforms, 21, 589-605.

Nalpanis, P., J. C. R. Hunt, and C. F. Barrett (1993), Saltating particles over flat beds, J. Fluid Mech., 251, 661-685.

Nield, J., and A. Baas (2008), Investigating parabolic and nebkha dune formation using a cellular automaton modelling approach, Earth Surf. Process. Landforms, 33, 724-740.

Nikuradse, J. (1933), Laws of flow in rough pipes (1950 translation), Tech. Rep. Technical Memorandum No 1292, National Advisory Committee on Aeronautics, Washington, D. C.

Okin, G. (2008), A new model of wind erosion in the presence of vegetation, J. Geophys. Res., 113, F02S10, doi:10.1029/2007JF000758.

Okin, G., and D. Gillette (2001), Distribution of vegetation in wind-dominated landscapes: Implications for wind erosion modeling and landscape processes, J. Geophys. Res., 106(D9), 9673-9683. 
Rasmussen, K. R., and M. Sorensen (2008), Vertical variation of particle speed and flux density in aeolian saltation: Measurement and modeling, J. Geophys. Res., 113, F02S12, doi:10.1029/2007JF000774.

Raupach, M. R. (1991), Saltation layers, vegetation canopies and roughness lengths, Acta Mech. [Suppl], 1, 83-96.

Raupach, M. R., D. Gillette, and J. Leys (1993), The effect of roughness elements on wind erosion threshold, J. Geophys. Res., 98(D2), 3023-3029.

Raupach, M. R., J. J. Finnigan, and Y. Brunet (1996), Coherent eddies and turbulence in vegetation canopies: The mixing-layer analogy, Boundary-Layer Meteorol., 78(3-4), 351-382.

Ross, A. N. (2008), Large-eddy simulations of flow over forested ridges, Boundary-Layer Meteorol., 128, 59-76.

Shao, Y., and A. Li (1999), Numerical modelling of saltation in the atmospheric surface layer, Boundary-Layer Meteorol., 91, $199-225$.

Shao, Y., and H. Lu (2000), A simple expression for wind erosion threshold friction velocity, J. Geophys. Res., 105(D17), 22,437-22,443.

Shao, Y., and M. R. Raupach (1992), The overshoot and equilibration of saltation, 97(D18), 20,559-20,564.

Shao, Y., M. R. Raupach, and P. Findlater (1993), Effect of saltation bombardment on the entrainment of dust by wind, 98(D7), $12,719-12,726$.

Shaw, R. H., and U. Schumann (1992), Large-eddy simulation of turbulent flow above and within a forest, Boundary-Layer Meteorol., 61, 47-64.

Skidmore, E. (1966), Wind and sandblast injury to seedling green beans, Agron. J., 58, 311-315.

Sterk, G. (2003), Causes, consequences and control of wind erosion in Sahelian Africa, Land Degrad. Develop., 14, 95-108.

Sutton, S., and C. McKenna-Neuman (2008a), Variation in bed level shear stress on surfaces sheltered by nonerodible roughness elements, J. Geophys. Res., 113, F03016, doi:10.1029/2007JF000967.

Sutton, S., and C. McKenna-Neuman (2008b), Sediment entrainment to the lee of roughness elements: Effects of vortical structures, J. Geophys. Res., 113, F02S09, doi:10.1029/2007JF000783.

Udo, K., and S. Takewaka (2007), Experimental study of blown sand in a vegetated area, J. Coastal Res., 23, 1175-1182.

Ungar, J. E., and P. K. Haff (1987), Steady state saltation in air, Sedimentology, 34, 289-299.

Van de Ven, T., D. Fryrear, and W. Spaan (1989), Vegetation characteristics and soil loss by wind, J. Soil Water Conserv., $44,347-349$.

Werner, B. T. (1990), A steady-state model of wind-blown sand transport, J. Geol., 98(1), 1-17.

Wolfe, S., and W. Nickling (1993), The protective role of sparse vegetation in wind erosion, Prog. Phys. Geog., $17,50-68$.

Xue, M., K. K. Droegemeier, and V. Wong (2000), The Advanced Regional Prediction System (ARPS)—A multi-scale nonhydrostatic atmospheric simulation and prediction model. Part I: Model dynamics and verification, Meteorol. Atmos. Phys., 75(3-4), 161-193.

Xue, M., K. K. Droegemeier, V. Wong, A. Shapiro, K. Brewster, F. Carr, D. Weber, Y. Liu, and D. Wang (2001), The Advanced Regional Prediction System (ARPS) - A multi-scale nonhydrostatic atmospheric simulation and prediction tool. Part II: Model physics and applications, Meteorol. Atmos. Phys., 76(3-4), 143-165.

Yang, B., M. Raupach, R. H. Shaw, K. T. Paw U, and A. P. Morse (2006), Large eddy simulation of turbulent flow across a forest edge. Part I: Flow statistics, Boundary-Layer Meteorol., 120, 377-412.

Youssef, F., S. Visser, D. Karssenberg, G. Erpul, W. Cornelis, D. Gabriels, and A. Poortinga (2012), The effect of vegetation patterns on wind-blown mass transport at the regional scale: A wind tunnel experiment, Geomorphology, 159-160, 178-188. 